\title{
Interfaces
}

INTERFACES Image Texte Language

$46 \mid 2021$

Jeux de Formats (2)

\section{Entretien avec Christine Delbecq, plasticienne}

Valérie Morisson et Christine Delbecq

\section{(2) OpenEdition}

Journals

Édition électronique

URL : https://journals.openedition.org/interfaces/4005

DOI : $10.4000 /$ interfaces. 4005

ISSN : 2647-6754

Éditeur :

Université de Bourgogne, Université de Paris, College of the Holy Cross

\section{Référence électronique}

Valérie Morisson et Christine Delbecq, «Entretien avec Christine Delbecq, plasticienne », Interfaces [En ligne], 46 | 2021, mis en ligne le 15 décembre 2021, consulté le 18 juin 2022. URL : http:// journals.openedition.org/interfaces/4005; DOI : https://doi.org/10.4000/interfaces.4005

Ce document a été généré automatiquement le 18 juin 2022.

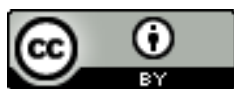

Les contenus de la revue Interfaces sont mis à disposition selon les termes de la Licence Creative Commons Attribution 4.0 International. 


\title{
Entretien avec Christine Delbecq, plasticienne
}

\author{
Valérie Morisson et Christine Delbecq
}

Christine Delbecq vit et travaille à Saint-Apollinaire, en Côte d'or. Elle est diplômée de l'École des Beaux-Arts de Mâcon (1978). Au cours de sa carrière, elle a cherché à mettre en forme une interrogation profondément humaine et existentialiste: comment tenir debout? Depuis ses premiers travaux, déclinaisons de colonnes vertébrales, jusqu'à ses récentes installations faites de blocs évidés et de fragments assemblés en un tout instable, elle n'a eu de cesse de réfléchir à ce qui nous fait tenir. Cet entretien a été écrit après une rencontre à l'église Saint Philibert (Dijon), lors de l'exposition On a penché l'horizon, et une visite de l'atelier de l'artiste. Nous la remercions pour son généreux accueil. Pour mieux la connaître, vous pouvez visiter son site à Accueil site : Christine Delbecq (free.fr).

VALÉRIE MORISSON : Votre parcours d'artiste est avant tout une quête formelle puisque, après avoir, au début de votre carrière, réalisé des tissages de grande taille, structurés par une armature métallique, vous avez ensuite travaillé autour de leurs squelettes, tout en continuant à dessiner. Puis est venu un temps où vous avez traduit votre réflexion sur ce qui nous fait tenir debout, qui s'est traduit par de multiples figurations de pieds. Le chemin est donc long qui vous a mené jusqu'à vos travaux récents où les papiers déchirés jouent un grand rôle. Pourriez-vous retracer brièvement ces évolutions et identifier le fil conducteur de ces recherches plastiques?

Christine Delbecq : Je me suis rendu compte pendant la grande exposition proposée en l'église Saint-Philibert de Dijon en juin et juillet 2021, à quel point, avec le temps, les questions de matières devenaient totalement indissociables des questions de sujets et de thèmes, au point qu'on ne peut savoir ce qui se met en branle en premier. J'ai en effet commencé par des sculptures tissées, ou mieux, des structures tissées me revient en écrivant le terme de structiles ${ }^{1}$, néologisme pour structure et textile, structure et fil, structure et fragile, qui résonne avec le contraste entre construit et précaire qu'on trouve dans mon travail. Ces grands structiles combinaient l'idée du squelette à celle du temps, voire du labeur, nécessaires à leur élaboration. Puis j'ai dépouillé l'architecture de ses tissages, pour me concentrer sur la structure, et de là 
j'ai glissé vers la notion de colonne vertébrale : comment être solidement souple dedans, pour être libre de forme dehors? Ces colonnes vertébrales - en céramique, en fil de métal, en dessin - m'ont occupée une dizaine d'années et se sont terminées par l'apparition d'éléments du corps : la bouche, ouverte sur le souffle, les narines, cherchant l'air, les genoux, mon tablier de peintre, et puis les pieds.

Figure 1. Colonne vertébrale.

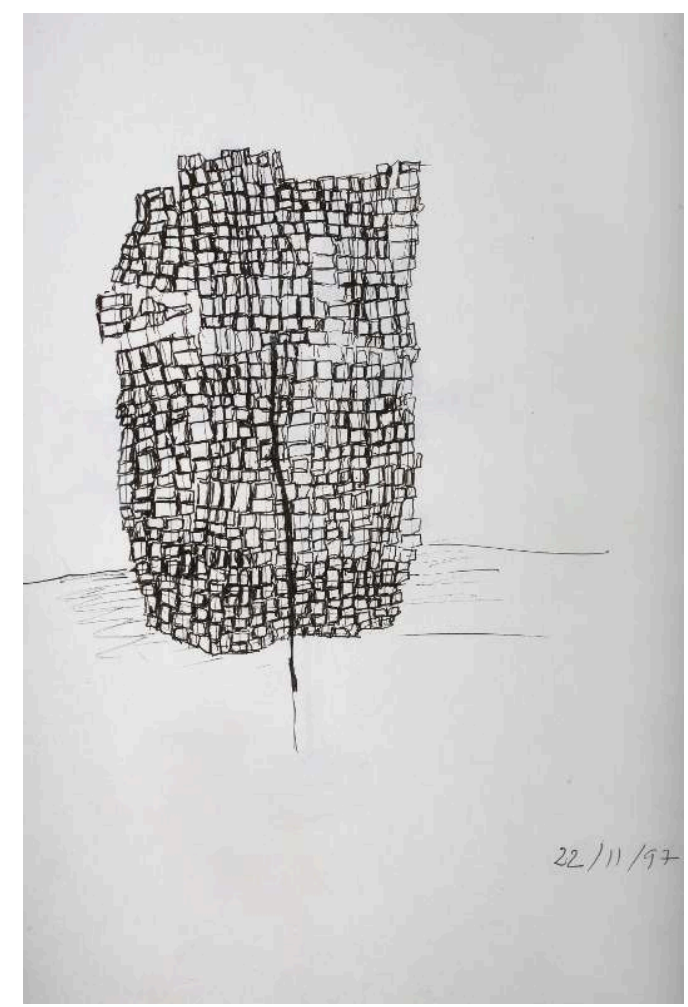

Stylo feutre sur papier. Dans carnets d'atelier. 20/30cm. 1997.

(C) Christine Delbecq.

J'ai dessiné puis peint des pieds - les miens, ceux d'amis, ceux de gens dans la rue acceptant que je dessine leurs pieds - pendant une douzaine d'années. J'interrogeais leur contact avec le sol, toutes les formes de sol, donc la tenue, la solidité, le mou. En même temps, je me suis mise à dessiner et peindre des blocs, un par un, deux par deux, avec le même questionnement sur le rapport au sol : pieds et blocs peints sur des toiles de deux mètres sur deux (les pieds n'y tenaient pas entiers) avant de se multiplier sur toutes sortes de surfaces et de se regrouper, emportés dans des mouvements de foule. 
Figure 2. Genoux.

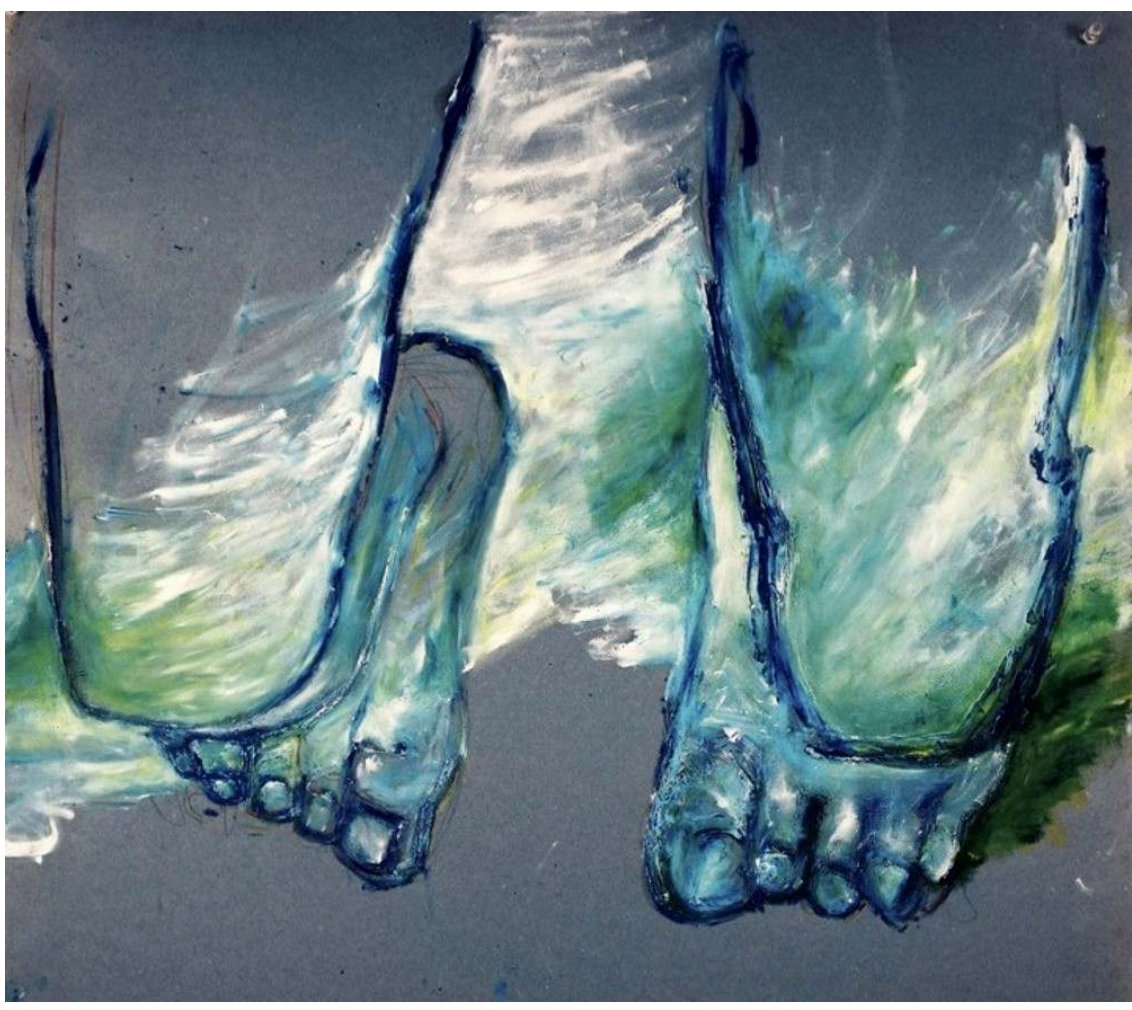

Huile sur papier gris marouflé sur bois. 100/90cm. 1998.

(C) Christine Delbecq. 
Figure 3a. Pieds froissés, série.

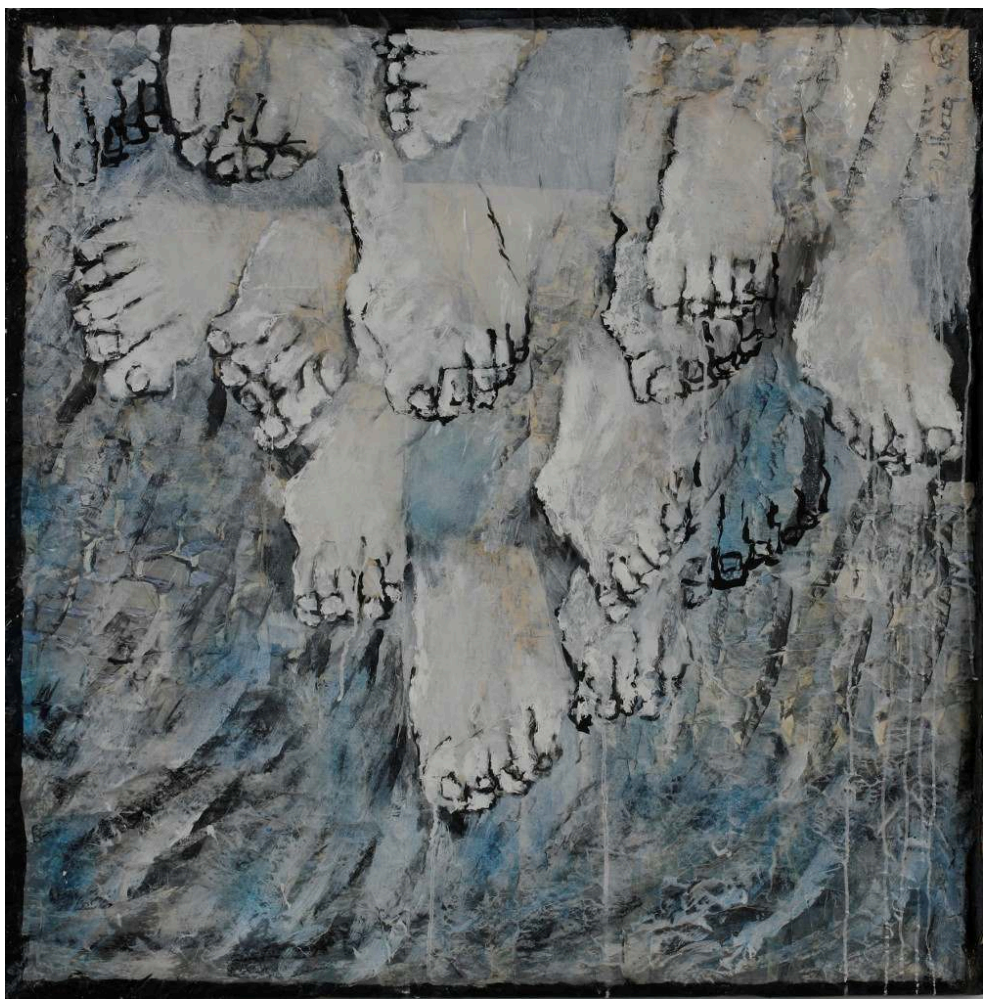

Acrylique et craies sur papiers de soie huilés et marouflés sur papier Tyvek, montés sur châssis. 100/100cm. 2006

(c) Christine Delbecq. 
Figure 3b. Les Ecorces Morris, série.

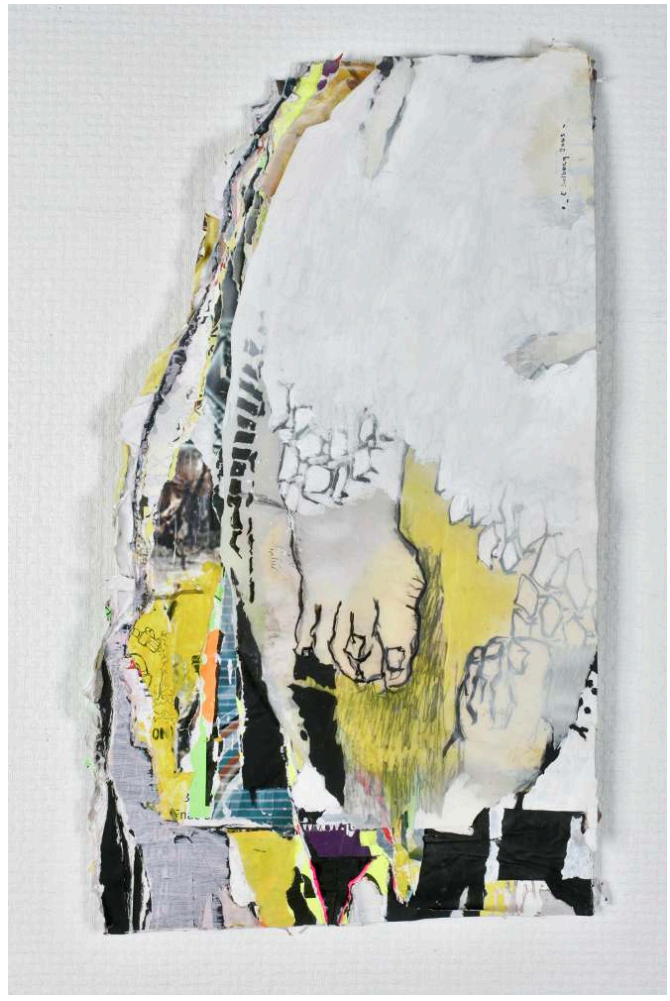

Acrylique, craie et huile sur papiers affiches récupérés, calque. Ici 50/75cm. 2004.

(c) Christine Delbecq.

J'ai compris que je peignais les sculptures que je ne pouvais pas réaliser, ne trouvant ni le matériau ni la technique qui auraient pu traduire l'immensité à laquelle je voulais me confronter. J'ai continué à chercher la simplicité de gestes et de matériaux avec lesquels je pourrais, seule, arriver à rendre ce qui m'habitait... Jusqu'au jour où j'ai trouvé ces blocs de carton évidés et recouverts de papier blanc. Je disais alors : " je quitte l'image, je fais les blocs ». J'ai commencé à les accumuler et à les assembler de façons diverses et parlantes pour moi, chaotiques ou construites. Je pense que cette mise en forme alliait la notion de structure (légère, simplissime, et sensible aux déformations, à la patine du temps) à celle d'écriture du temps, comme dans le tissage, ces grandes étendues qu'on construit tout petit bout par tout petit bout. 
Figure 4a. ChaosCartonFlaque, installation.

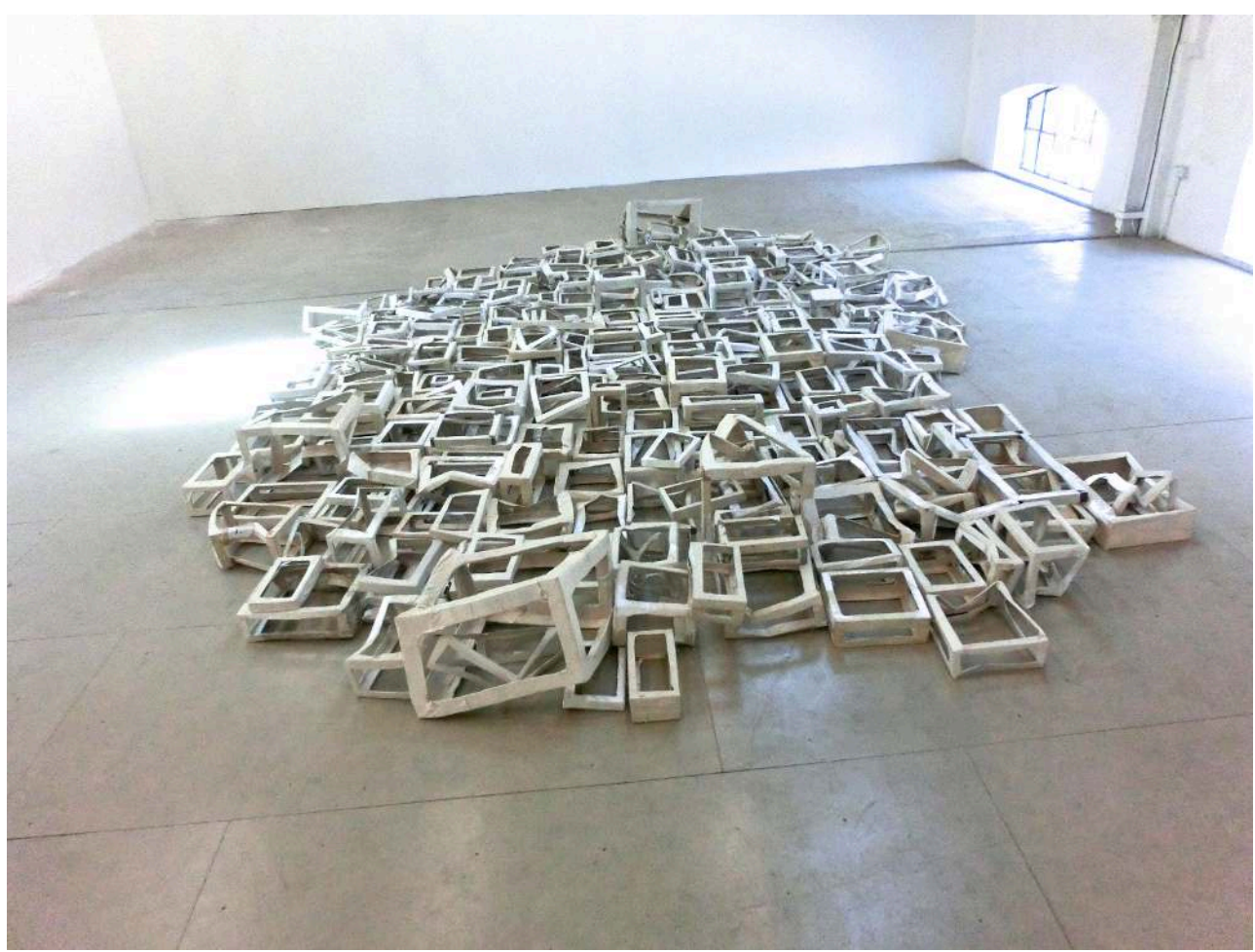

Configurations variables. Cartons évidés et recouverts de papier journal non imprimé. Ici 350/500cm environ. Depuis 2013. Ateliers Vortex, Dijon.

(c) Christine Delbecq. 
Figure 4b. ChaosCartonAngle, installation.

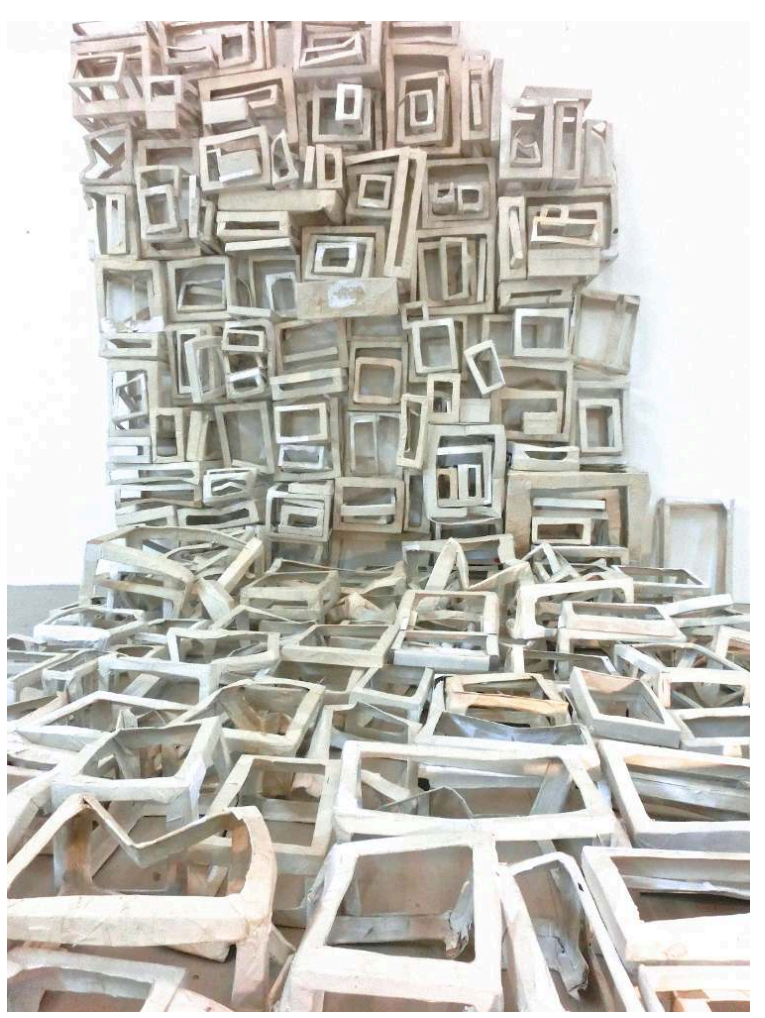

Configurations variables. Ateliers Vortex, Dijon.

(C) Christine Delbecq. 
Figure 4c. ChaosCartonMur. 2014/16. Série des Paysages du temps.

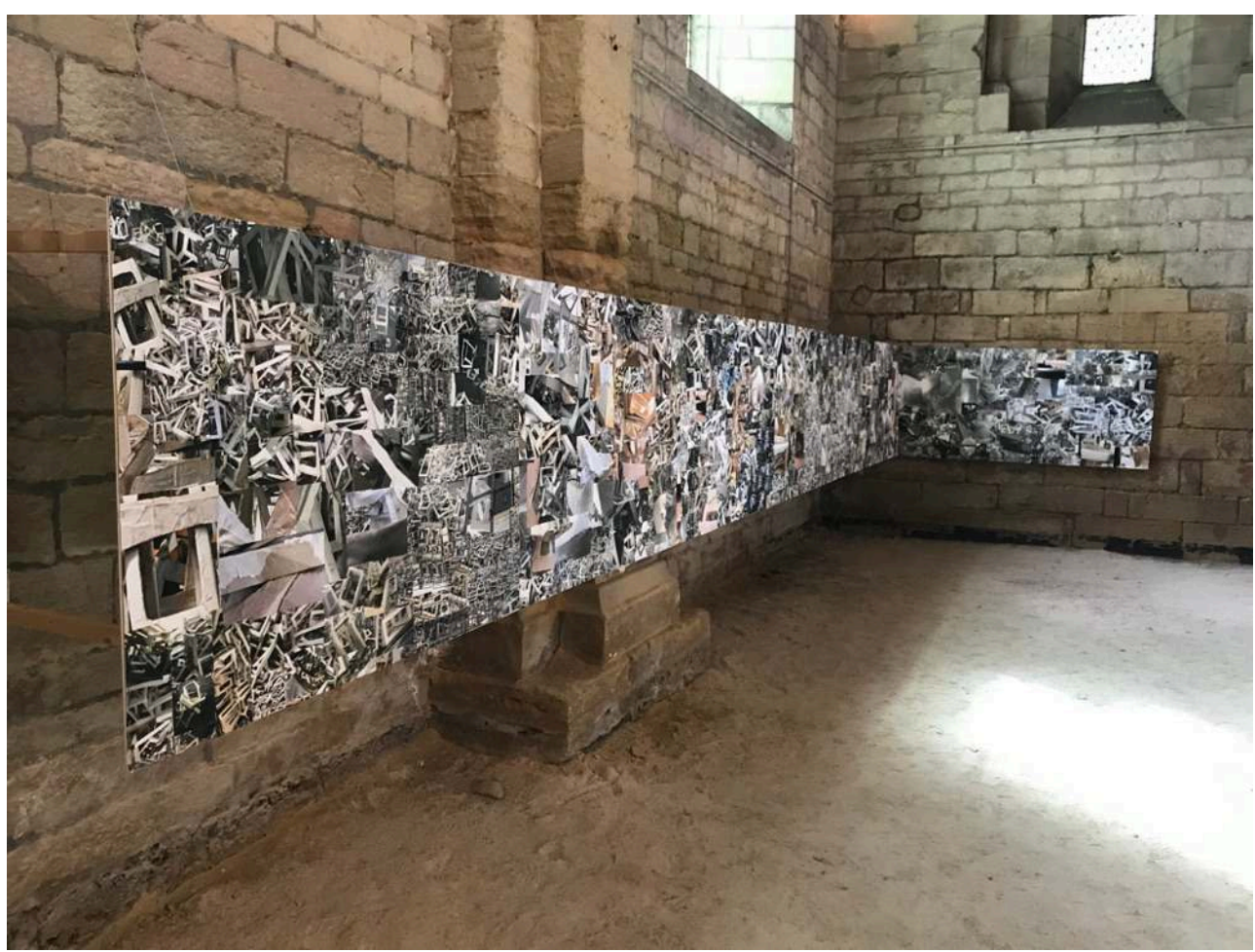

Modules de 100/200cm, configurations variables. Photographies tirées sur papier à peindre marouflées sur carton puis sur bois. Ici, 1000/100cm, église Saint-Philibert de Dijon, juillet 2021.

(c) Christine Delbecq.

J'ai commencé à garder les traces de tout ce que je faisais, à photographier les milliers de détails qui m'occupaient intérieurement dans chaque chantier d'œuvres pendant que j'élaborais mes structiles, et, plus tard, à les recomposer en très grands panneaux de photos assemblées. Ces traces sont comme un journal de travail, un paysage du temps. Plus tard, je suis arrivée aux déchirements de papier: j'agrafe assidûment des feuilles de papier A4 sur de grandes plaques de bois puis les arrache par lambeaux, et je cours avec l'agrafeuse après ces lambeaux qui voltigent, dans une sorte de jeu plutôt gai - de mon point de vue - entre décision et hasard, ordre et dispersion, puissance et précarité. Pendant le confinement, je me suis mise à photographier par milliers non plus mon travail, mais les brins d'herbe de ma marche quotidienne: parce que je marche et que cette marche vulgaire, toute simple, est devenue au fil du temps le reflet, ou l'origine, du rythme intérieur du travail. 
Figure 5a. SoulèvErts Carré, série.

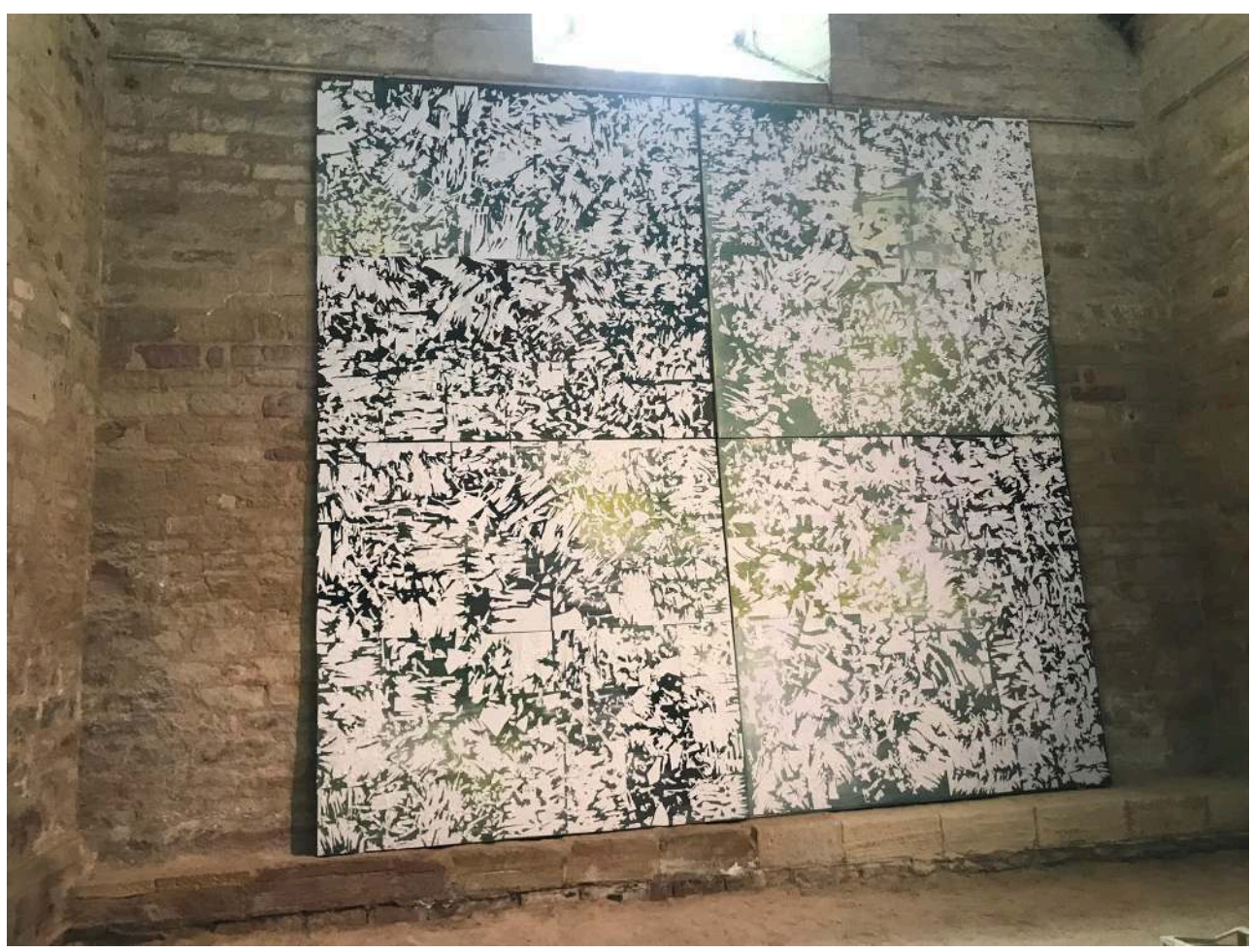

Papier machine, agrafes, contreplaqué peint. Ici quatre fois 200/200cm. église Saint-Philibert de Dijon, juillet 2021

(c) Christine Delbecq 
Figure 5b. LaRivièreVerte. 2020. Série des Paysages du temps.

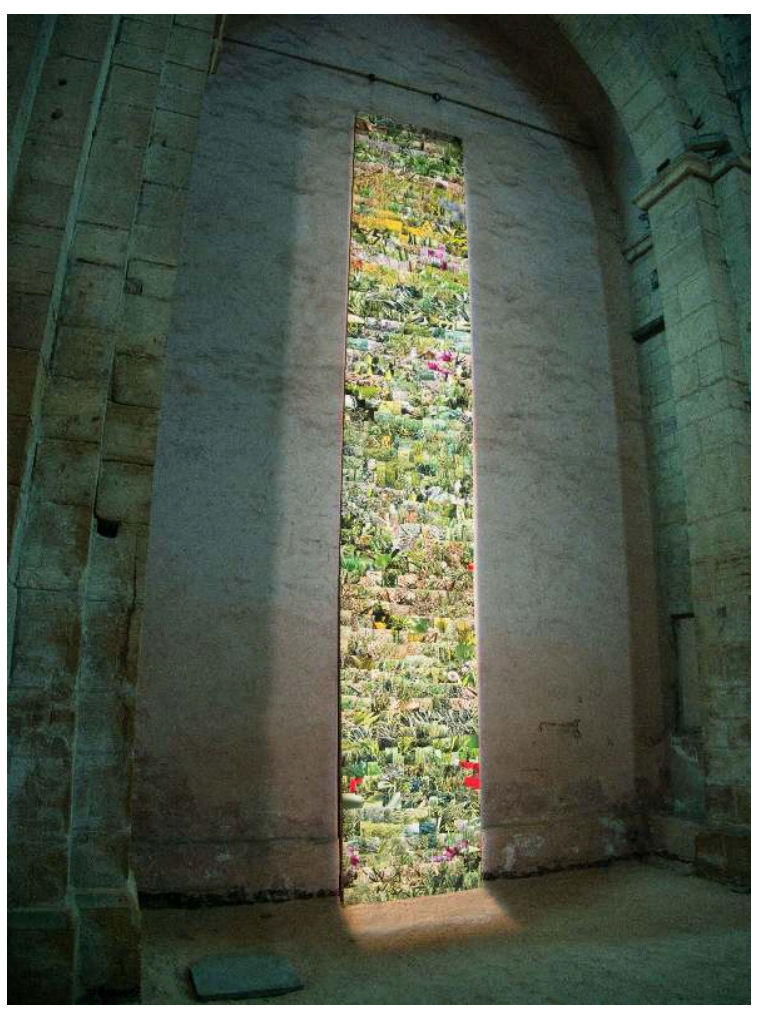

Photographies tirées sur papier à peindre mat marouflées sur bois. Modules de 250/120cm, configurations variables. Ici 7500/120cm, église Saint-Philibert de Dijon, juillet 2021.

(C) Christine Delbecq.

Ainsi, passer de la colonne vertébrale au pied, du pied au bloc, du bloc au sol, du sol à l'écriture, puis aux constructions fragiles, passer des Paysages du temps au travail sur l'herbe, que j'ordonne en lignes successives ou amasse en piles de feuillets légers, me semble relever d'un cheminement - chemin - que je découvre en me retournant plus que je ne le décide, mais qui se dessine, lui, assez fermement.

vм : Vous avez collaboré avec des poètes, illustré un recueil puis réalisé des lettres d'un format très particulier. Comment définiriez-vous le rapport de votre travail au langage et à la forme du livre?

CD : Chaque fois que j'ai travaillé avec un poète c'était d'abord une histoire de rencontre. Rencontre avec l'auteur, ou l'éditeur. Quand l'auteur réagit à l'une de mes œuvres, j'attends de découvrir, avec une émotion presque anxieuse, ce que l'accompagnement littéraire me révèlera éventuellement de mon travail. S'il m'est demandé de résonner avec un texte, j'essaie de trouver une expérience de travail simple qui, dans le petit format d'un livre, me permettra de retrouver la sensation d'étendue - géographique ou temporelle - dont j'ai besoin : ça induit la notion de série. La répétition et la déformation d'un seul geste, ou d'une seule forme, me permettent de faire comme une marche, d'une page à l'autre, dont chaque station serait assez pleine pour habiter la page. Et puis les livres sont des compagnons vitaux pour moi, depuis une enfance maladive. Toutes sortes de livres. C'est toujours un cadeau que je me fais de m'octroyer le temps de lire. Ils ont probablement contribué à mon goût pour la précision ou l'association des mots. Ce qui me parle le plus en poésie est son pouvoir nettoyant pour l'oreille et la pensée, qui naît du texte, de 
l'agencement des mots ou du suspens entre les mots. J'aimerais trouver une sorte d'équivalence plastique à ces chocs bénéfiques.

Figure 6. Les oiseaux, une sur 17 illustrations.

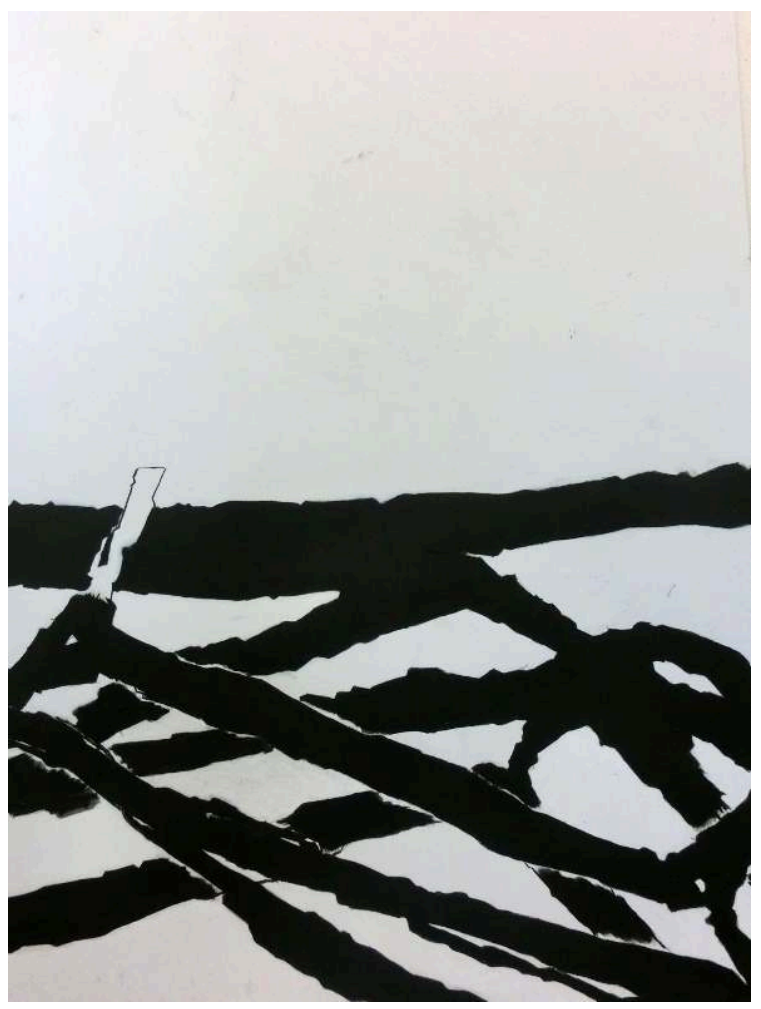

Dans Les colibris à reculons, recueil Sabine Huynh - Christine Delbecq, éditions Voix d'encre.

(c) Christine Delbecq.

vм: Dans L'Echange (2012-2014), un travail que vous reprenez en ce moment, vous proposez un format très singulier: des lettres sans mots, des inscriptions qui oscillent entre le paysage, celui du Groenland où vous avez observé des blocs de glaces, et l'écriture. Parlez-nous de ce projet que vous rapprochez d'une poétique oraculaire.

CD : J'ai, grâce à une amie danoise, eu la chance de réaliser un rêve d'enfance : je suis partie avec elle marcher trois semaines au Groenland en juillet 2009. L'hiver précédent, je peignais des blocs de rochers dans de l'eau grise et blanche, sur une très grande toile déroulée au sol, sur laquelle je voulais que les gens puissent marcher. L'année précédente, j'avais peint deux très grandes toiles, Le tricot des jours et Le piège à souris, qui assemblaient en lignes ou en désordre de très petits blocs parallélépipédiques. Mes blocs devenaient, par leur répétition, la représentation de mes journées, ou des mots. Sur les bateaux et devant l'océan, j'ai dessiné pendant trois semaines des lignes d'icebergs, accrochés d'abord aux lignes des cahiers d'écoliers que j'avais achetés à Ilulissat, puis alignés sur un fil d'horizon. C'est lentement qu'est venue l'idée d'envoyer des lettres, peut-être pour répondre au désir insatisfait de percevoir l'impact que mon travail pouvait avoir sur les gens. Sur du tissu blanc, par la suite sur des feuillets de plastique, j'ai aligné des mots-blocs en papiers d'affiches déchirés et collés, sertis de traits noirs; ou bien j'ai évidé les supports, j'ai rassemblé les morceaux récupérés dans des filets de gaze; ou je les ai recousus. J'ai aussi déchiré et découpé le tissu ou le plastique, matériaux de mes courriers, j'ai fabriqué des boules, des accordéons, des pliages ; enfin j'ai expédié mes 
Lettres sans mots, en France et lors d'une résidence de deux mois dans un lycée de Montréal. Il y avait là encore un paradoxe, entre l'invention d'une écriture et la pulsion de la cacher. Comme me l'ont dit les élèves de l'Académie Dunton : « tu veux qu'on réponde à quelque chose que tu ne sais même pas avoir écrit?». C'était bien $\mathrm{vu}$ ! Cette phrase d'Yves di Manno a résonné : «Le noyau poétique réside bien là : dans ce déplacement, ce retrait de la parole telle qu'on en a couramment l'usage, au profit d'un discours que je ne veux pas qualifier d'oraculaire, mais qui semble émerger d'un autre territoire du langage ${ }^{2}$.»

Figure. 7a. Lignes d'iceberg dans les Carnets du Groenland.

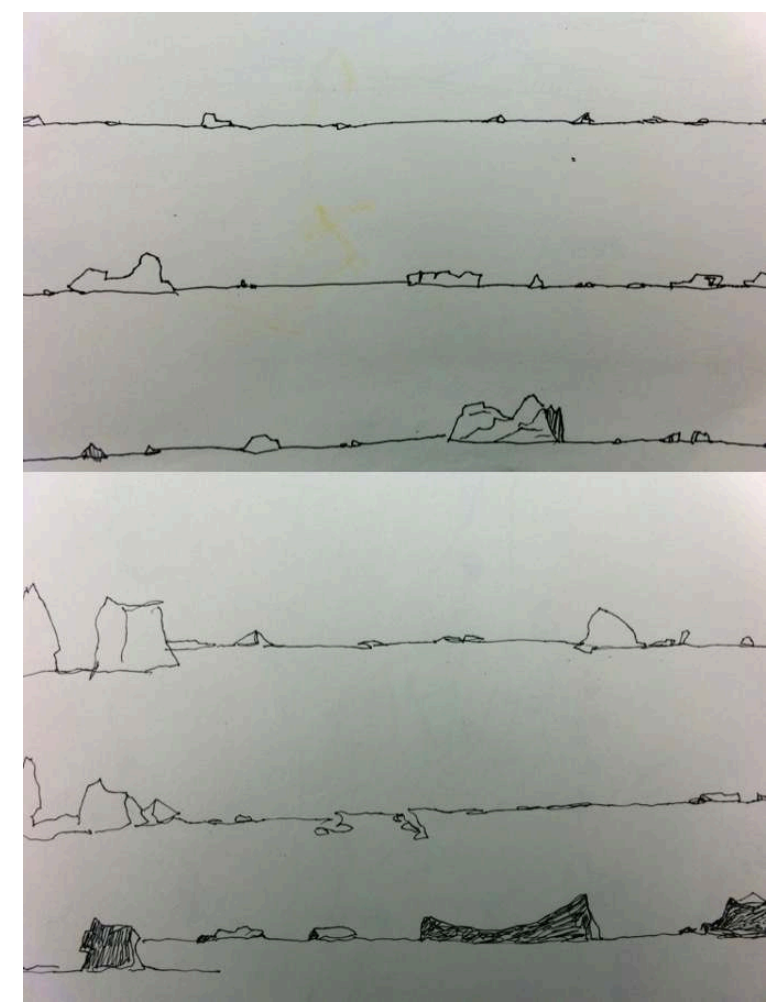

Feutre acrylique sur papier, deux fois 30/20cm. 2009.

(c) Christine Delbecq. 
Figure 7b. Les Livres blancs.

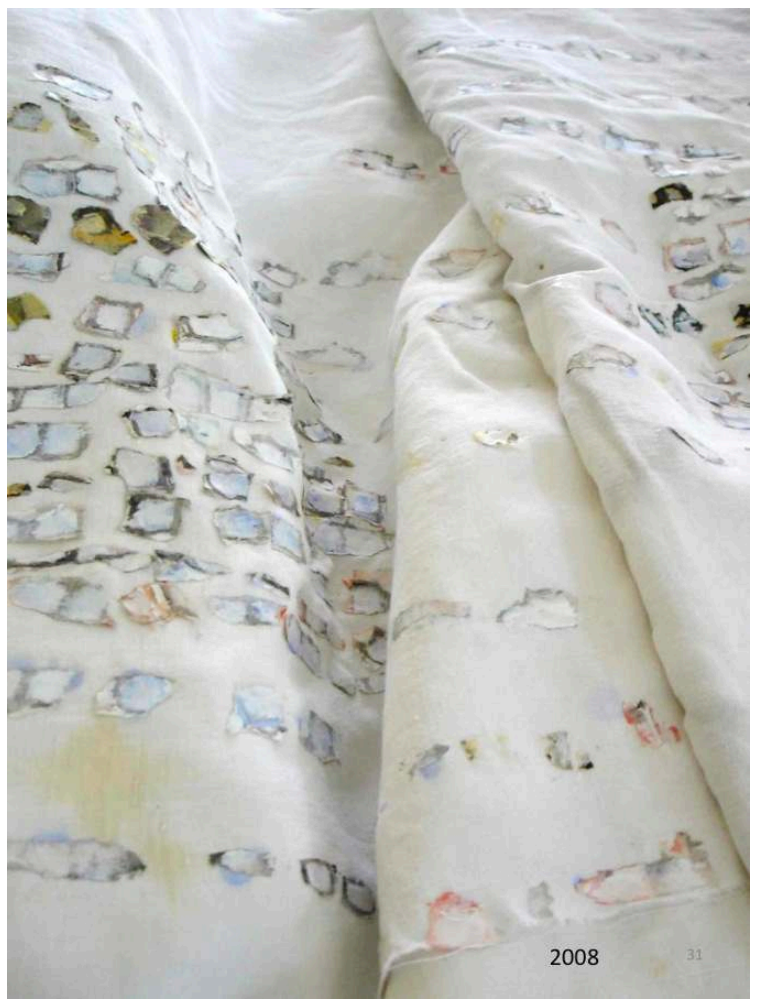

Papiers déchirés collés sur draps blancs cousus. Formats variables. 2011/12. (C) Christine Delbecq. 


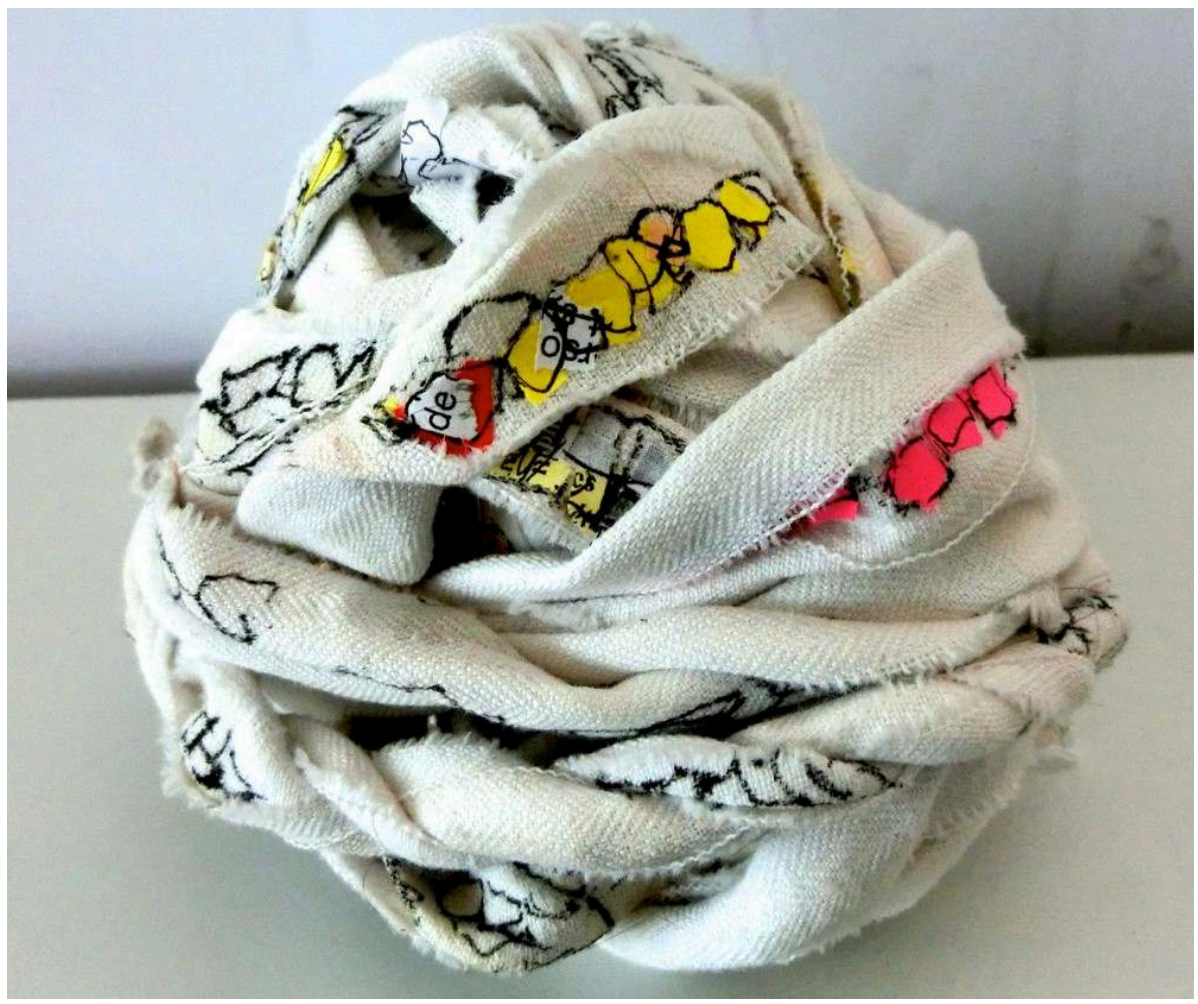

Papiers déchirés collés, feutre acrylique, drap blanc. Formats et configurations variables. 2013.

(c) Christine Delbecq.

VM : Vous avez, à un moment, essayé de travailler à partir de maquettes qui étaient ensuite agrandies. Pourquoi cette traduction de la forme dans un autre format ne vous a pas semblé satisfaisante?

CD : Je passais facilement des dessins aux petites sculptures en fils de fer soudés, je retrouvais dans leurs imperfections techniques la mobilité de fond qui m'est essentielle. Un ami m'a proposé de les agrandir en fer à béton, ce que je ne pouvais réaliser seule, et j'ai vu se perdre cette vitalité maladroite au profit d'une élégance formelle qui m'apparaissait figée. Depuis, cette question court: j'ai des séries de dessins, par exemple la série "Au lieu rouge », que je fais en m'imaginant clairement que je suis dans un lieu, une chambre rouge, et que les traits de papier déchiré que j'assemble sont les traces laissées dans l'air des élans d'une personne vers une autre. Mais, si je dois réaliser une installation à partir de ces projets, je vais entièrement réinventer une nouvelle situation, pour recréer la force fragile de l'instant. C'est le cas aussi, en ce moment, dans le passage au réel de la série des PenchéFil, petits structiles en carton-plume et fil à coudre. Ils ne sont jamais transposables par agrandissement fidèle, sans doute parce qu'à chaque fois, le changement nécessaire de matériau transformera la forme. 
Figure 8a. Fils et blocs, croquis.

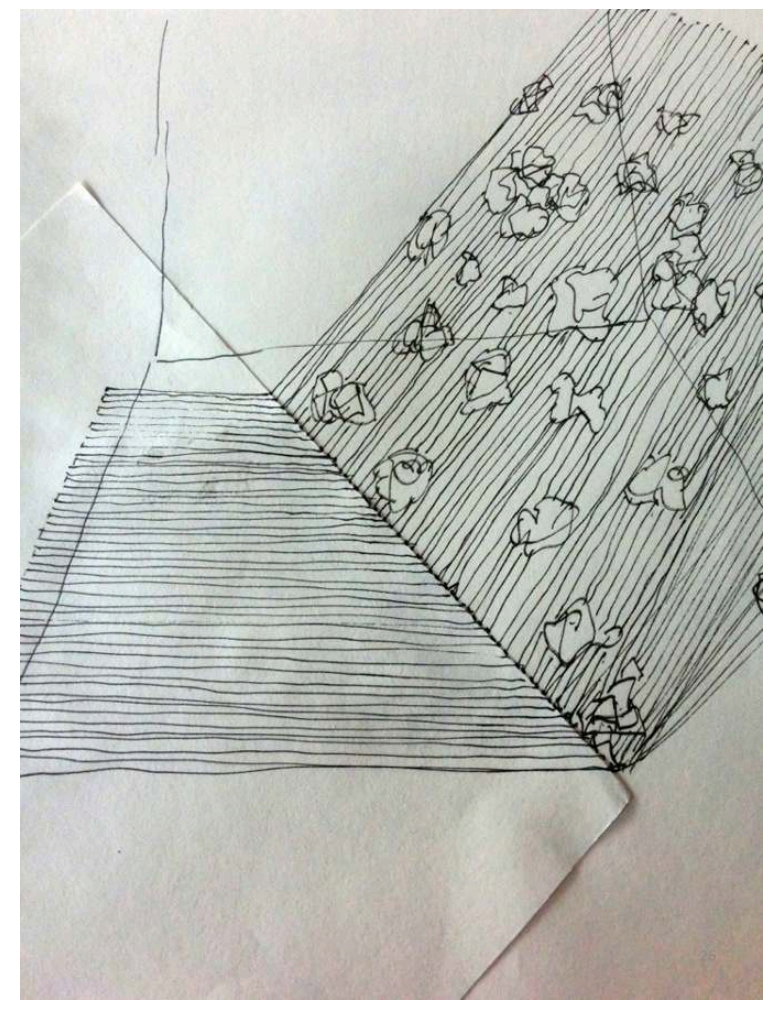

Feutre acrylique sur papier, collage. 22/30cm. 2009.

(C) Christine Delbecq. 
Figure 8b. PenchéFil, structile.

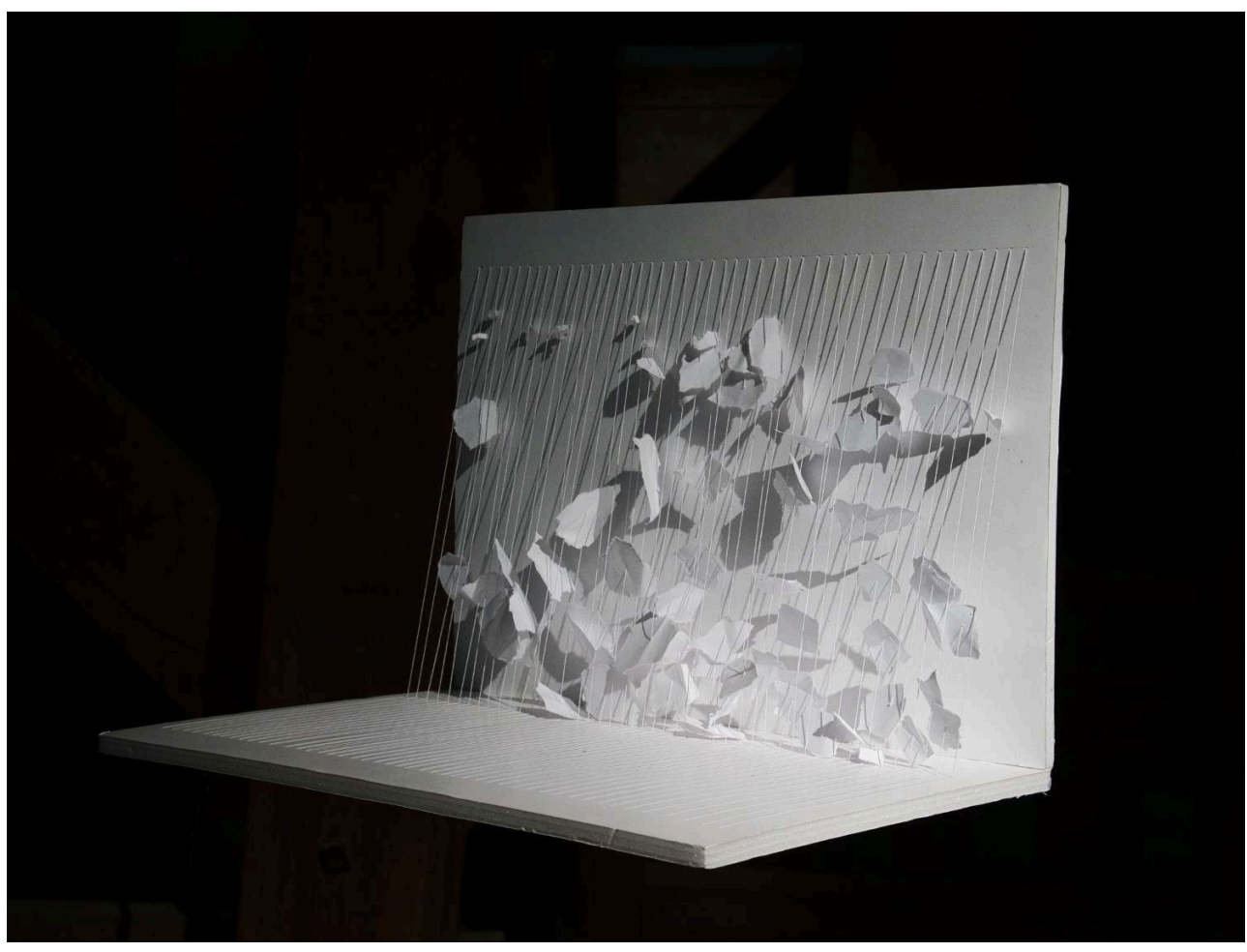

Papier machine, fil, carton plume. 30/40/28cm. 2019/20.

(c) Christine Delbecq.

Figure 8c. PenchéFil, installation, travail en cours.

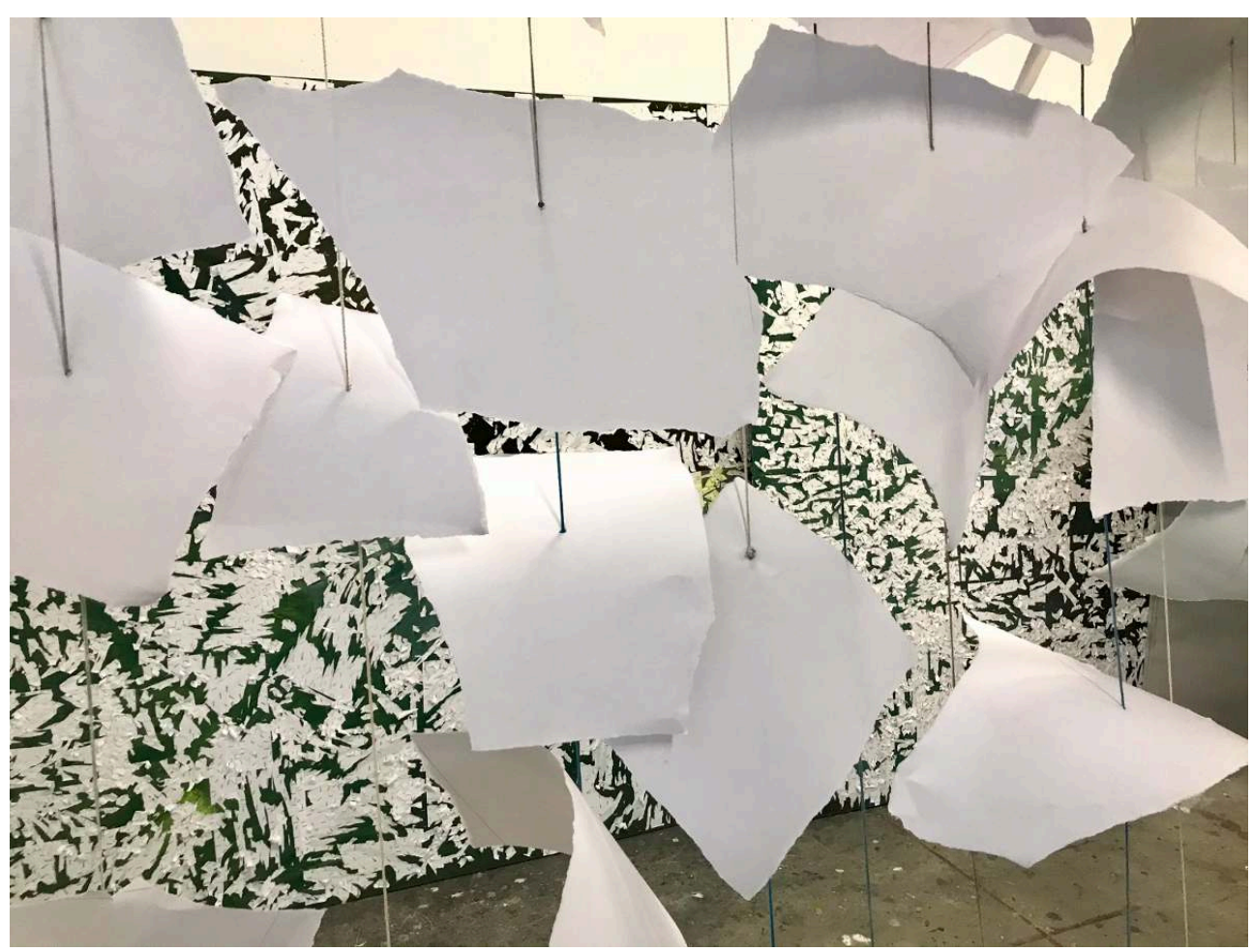

Papier canson, cordelette, briques. 2020/21.

(c) Christine Delbecq. 
vм : Vous parlez de votre attention aux détails des formes ou des matières comme étant au cœur de votre sensibilité. Pourtant beaucoup de vos œuvres sont des créations de grande taille qui mobilisent votre corps et occupent pleinement l'espace d'exposition. Comment mettre en relation le tout petit et le grand, parfois le monumental ?

CD : Je pense que dans les deux cas il y a une confrontation entre le corps et l'espace. Je pense qu'enfant, dans une atmosphère insécure qui me mettait en état de vigilance permanente, je ne regardais que les détails, pour les déchiffrer et savoir à quoi m'en tenir, comment me positionner, et parce que je manquais d'un calme suffisant pour savoir prendre de la distance. J'étais myope par essence! Je crois que, par mon travail, j'ai apprivoisé lentement les notions d'espace, de vide, et de distance. J'ai d'ailleurs appelé le paysage du temps lié à l'échange des lettres sans mots Le loinPrès.

Figure 9. LeLoinPrès (ici avec PiedsLanières, dessin. Huile et craie sur papier marouflé sur polycarbonate. $120 / 120 \mathrm{~cm})$.

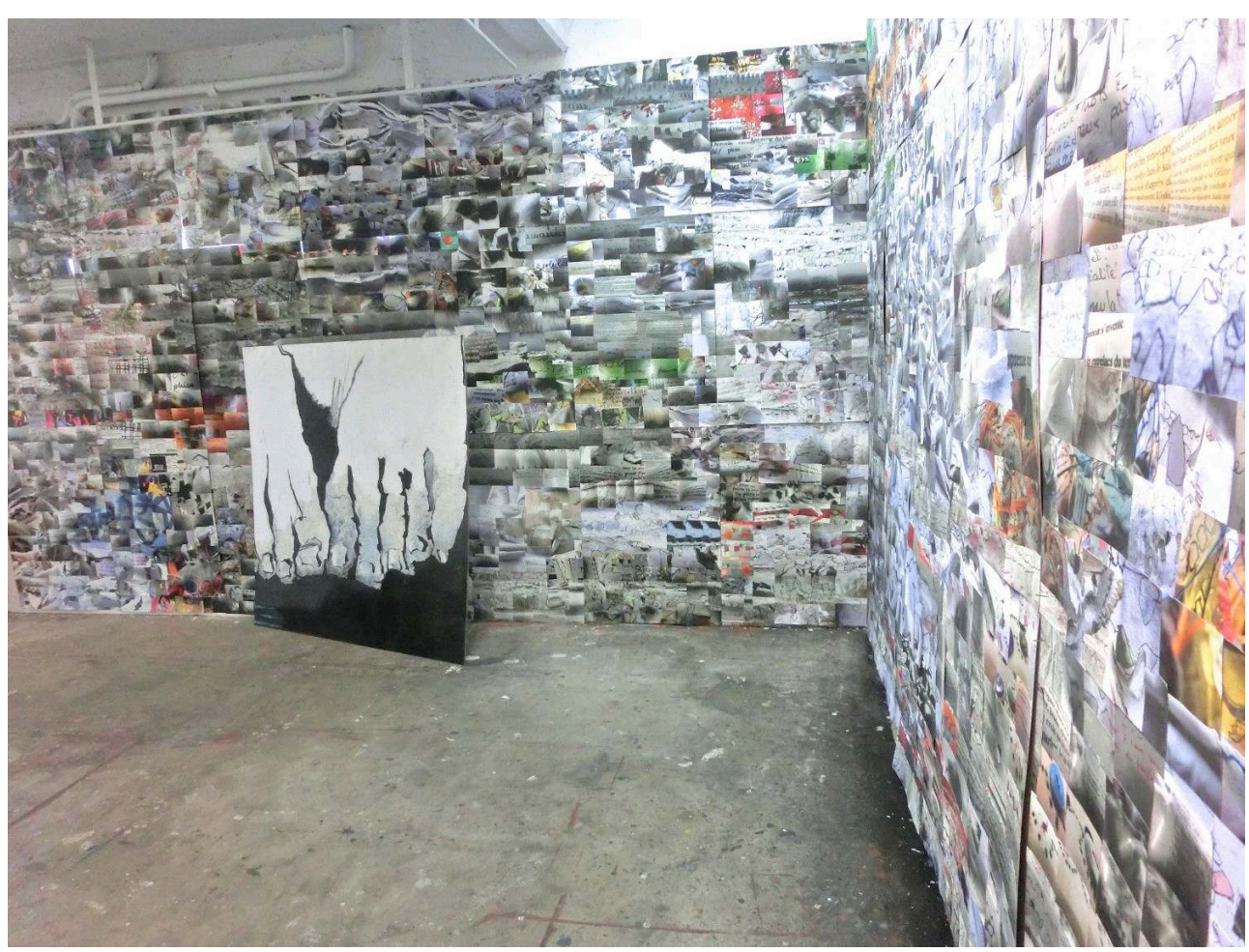

Série des Paysages du temps, détail. Configurations et dimensions variables. Photographies tirées sur papier à peindre mat marouflées sur carton puis sur bois. Ici dans l'atelier, 1700/330cm. 2014/16.

(c) Christine Delbecq.

Lorsque je travaille à de grandes installations, je dois constamment bouger autour d'elles, mobiliser mon corps pour les réaliser, j'en ai « plein les bras ». Le regardeur percevra l'œuvre de façon plurielle, active, en se déplaçant autour d'elle, sûrement sans s'occuper des détails qui se trouvent noyés dans la masse. Si je travaille en tout petit, c'est mon esprit qui, en adaptant de manière imaginaire ma taille à cet univers réduit, trouve la bonne échelle de regard. En arpentant l'espace autour de l'œuvre, ou en me projetant dans l'espace délimité par l'œuvre, je perçois la dimension monumentale du monde et je la vis, physiquement ou mentalement.

Lorsque j'agrandis un détail minuscule pris dans une de mes installations, lorsque je rends visible et hors de proportion quelque chose à quoi on ne faisait pas attention, j'ouvre un nouvel espace, qui confère au fragment un autre sens, ou je dilue une 
vision identifiée ; c'est une transmutation. En travaillant, je passe constamment d'une échelle à une autre, d'une interprétation (comme pour l'œuvre musicale) à une autre, dans un système d'aller-retour qui se nourrit de lui-même.

vM : L'idée de transmutation est perceptible dans des montages que vous avez réalisés à partir de vos dessins, reproduits ou convertis en plus grand format sur papier calque puis montés sur un cadre de sorte à constituer une boîte, à l'intérieur de laquelle vous glissez des réalisations dont on voit la présence floue sans en distinguer les contours exacts. C'est un dispositif très particulier qui pourrait s'apparenter à un reliquaire personnel et qui invite le spectateur à accepter de n'avoir pas accès à l'élément secret inséré entre les feuilles de calque. Ces œuvres mystérieuses, entre peinture et sculpture, déploient un imaginaire de l'opacité qui peut-être rejaillit dans d'autres travaux. Vos préférences semblent d'ailleurs aller vers des matières ou supports que j'appellerai volontiers membranes. Comment appréhendez-vous cette dialectique entre la visibilité et l'invisibilité?

CD : Dans ce travail il y avait deux choses : j'ai photocopié en plusieurs dimensions et par centaines les dessins de pieds accumulés dans mes carnets (les pieds de personnes de mon entourage) puis je les ai collés, ou retranscris au crayon de papier, sur des feuilles de papier de soie mises à sécher seulement tenues par deux punaises, ce qui laissait à la colle la liberté de déformer le papier. Un ami passé à l'atelier me dit : « ils sont très bien, mais ils font peur aussi, c'est hard ». Je les ai alors insérés entre deux feuilles d'un papier calque plastique, parfois incisé pour qu'un bout de la forme en volume dépasse, jouant à cacher et montrer tout à la fois. Vous parlez de membrane, on pourrait penser à des cocons; il s'agit bien d'une matière vivante, mal définie, dont je propose une étape mais dont la forme définitive reste à envisager, plus qu'à montrer. Si reliquaire, ce serait le reliquaire d'un morceau d'énergie, et de matière, dont la forme serait laissée disponible pour l'imaginaire, ou l'expérience, de chacun. Qu'y a-t-il là-dedans ? Qu'est-ce que je peux en faire? 


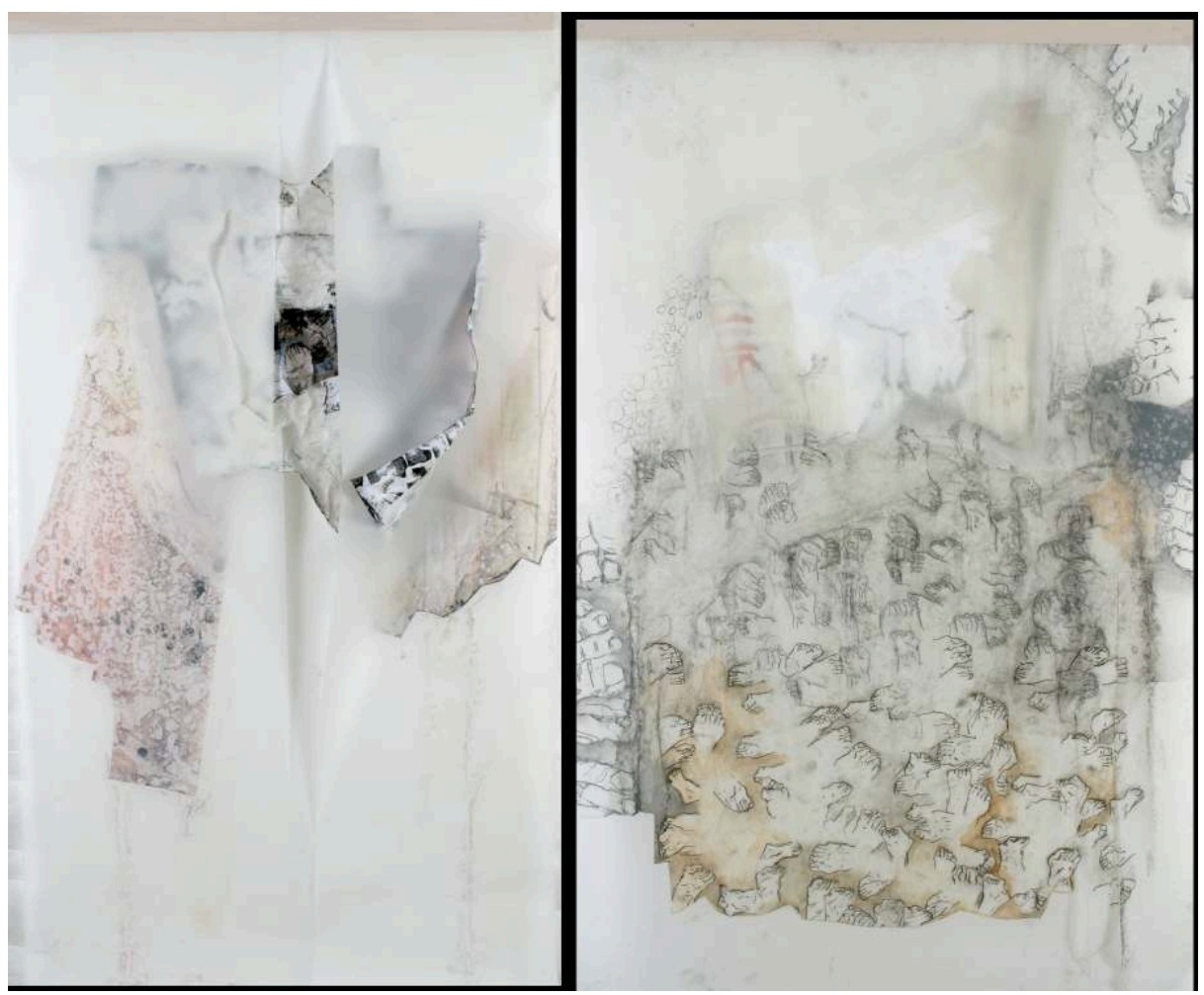

Crayon de papier, crayon de couleur, huile d'oeillette sur papier indéchirable entre deux calques plastiques. Deux fois 88/144cm. 2003.

(C) Christine Delbecq.

vм: Le travail de Richard Serra vous intéresse particulièrement. Pouvez-vous nous expliquer ce qui retient votre attention dans son œuvre?

CD : J'avais acheté, il y a une trentaine d'années, une cassette où Richard Serra parlait de son travail. Je ne me rappelle pas d'images. Mais je me souviens de cette anecdote qu'il racontait : enfant, il passait devant la mer pour aller à l'école et il se rappelait qu'il ne voyait pas du tout la même chose à l'aller et au retour. Ça m'a frappée de justesse, le fait qu'un travail puisse s'appuyer sur un détail apparemment aussi banal, aussi universel, mais dont l'artiste, par une singularité d'attention et de résonance intérieure, va faire un processus. C'est comme l'histoire de la pomme que le père de Giacometti lui faisait dessiner, et que de gommage en gommage l'enfant amenuisait sans cesse jusqu'à ce qu'elle lui plaise. Des années plus tard, en voyant passer au loin dans la rue Maindron un couple sous la pluie, Giacometti s'est aperçu que c'était là son rapport privilégié de distance au monde. Serra m'a aussi ouverte à l'interrogation du poids réel des œuvres, à leur matérialité et à la participation corporelle des regardeurs. Souvent, c'est un tout petit détail d'une œuvre ou de la parole d'un artiste qui vous met en branle. Qui prend pour vous un sens immédiatement appréhendable et moteur.

vм : Une grande partie de vos œuvres fait dialoguer le fragment, le débris pourrait-on dire dans certains cas, et le tout. Des blocs à la fois épars et formant un ensemble dans certaines installations, des bouts de papiers liés ensemble par de frêles attaches, des bribes de photographies assemblées en overall. Vous m'avez expliqué être émue par l'idée que nous sommes, nous-mêmes, de négligeables éléments d'un tout, tout à la fois 
minuscules et grands. C'est cette idée qui préside à ces jeux de variation d'échelle dans vos œuvres?

CD : Je pense. Sa sensation plutôt. Notre énormité (encombrante) à l'échelle de nos vies personnelles, la place que nous y prenons tout en vivant notre " minusculité » à l'échelle du monde, m'ont toujours obsédée; peut-être bien depuis mes lectures répétées, lorsque j'étais enfant, du roman illustré de Jonathan Swift, Les Aventures de Gulliver. J'ai passé des heures à regarder ce corps géant retenu par tous les filins accrochés aux petits piquets fichés au sol. Je pense que l'image plastique m'émerveillait, plus que le sens du roman ne m'occupait. Je me suis souvent demandé pourquoi les gens ne parlent pas davantage de cet écart, comment ils se débrouillent - mieux que moi sans doute - avec ce sentiment d'étouffement, parfois, devant la colossalité de ce qui nous occupe au quotidien, et la sensation d'une pulvérisation de notre vie dans la chute du monde.

Vous relevez bien ces autres éléments importants, celui de la globalité dans le détail et inversement, et le côté ténu, en bribes. J'ai mis longtemps à trouver mes matières (papier machine, journal non imprimé, carton récupéré, fil à coudre, contreplaqué fin, bâches plastique fines), à simplifier les gestes, les outils, à enlever les formes, à ne garder qu'une énergie au fondement de chaque œuvre. Les réponses que j'ai reçues aux Lettres sans mots m'ont fait comprendre qu'il fallait que j'accepte que mon travail puisse être perçu de manières diverses et imprévues. De même que je reconnais qu'une part importante de ce que je fais m'échappe, je vis sereinement à présent le fait que ceux qui regardent emmènent ce que je fais là où ils sont. Certains de mes structiles semblent des échos de ceci : c'est tout en bribes, tout en dérisoire, tout prêt à s'échapper, et pourtant relié par des fils en équilibre, ou légèrement tenus par des agrafes. On me dit parfois que certaines œuvres sont violentes; je les vois aussi comme un jeu, un équilibre se cherchant entre tenir et lâcher. 
Figure 11. PenchéFil, détail.

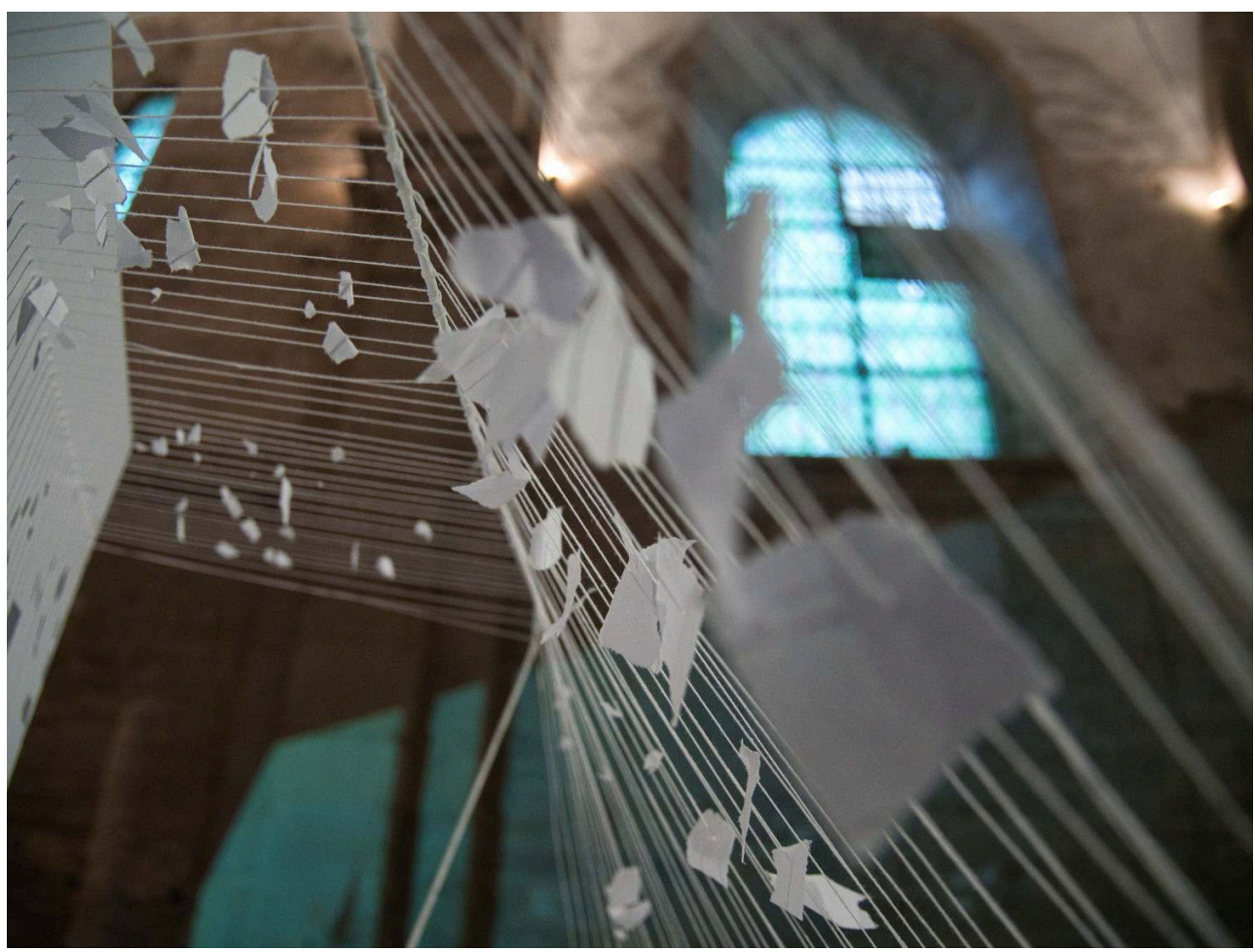

Papier machine, fil à coudre, carton plume. 2020.

(C) Christine Delbecq

Je crois que la puissance du fragile m'enchante. J'ai eu longtemps, dans l'atelier, une photographie d'un autoportrait d'André Breton : son profil constitué du trait de son crayon allié à un fragment de moulage en papier de sa joue me fascinait. Le presque rien qui prend vie et se pare de puissance. J'aimerais arriver à ça plastiquement. Dans mon usage de la photographie, il y a aussi quelque chose de paradoxal : je sélectionne avec soin sur mon ordinateur les détails qui me parlent alors que j'ai photographié à l'aveugle, en posant l'appareil photo sur le sol ou sur mes œuvres : j'ai descendu l'oeil dans mes pieds. Mais aussi lorsqu'ensuite je rassemble ces détails bien choisis et les regroupe par centaines sur le mur, ou en diaporama. Je les noie, je les perds à nouveau, au profit de la masse et de son énergie. L'énergie avant l'image.

vм : Vous dissociez la matière, vous créez des fragments pour ensuite, par un processus de réagencement et d'accumulation, ré-assembler, reconstruire en laissant apparentes les fractures et sutures. Y-a-t-il dans ce processus quelque chose de métaphorique qui toucherait à la réparation, la résilience, le soin ou care?

CD : Bien sûr je pense que toute création est une forme de soin, en tous cas de pari sur le vivant: je me rappelle m'être dit que dans ce seul endroit de l'atelier j'aurais une forme de pouvoir sur les choses, sur quelque chose qui m'appartiendrait et que personne ne pourrait m'enlever. J'ai ouvert mes ateliers à destination des enfants et des adultes avec cette expérience et cette certitude ancrées, mais tues. À chacun sa route. Je ne sais pas si les coutures, les fractures, sont de l'ordre du soin. Pour moi c'est une franchise, et de la simplicité. On m'a reproché le peu de soin que je prendrais de mes œuvres, mes gestes désinvoltes à leur égard, voire leur présentation maladroite. Je sens maintenant l'intérêt de la finalisation de chaque chose, la présentation marquant vraiment le bout de la recherche. Mais il m'a fallu d'abord 
énormément résister, avec l'impression de dévoyer, de tricher, si je plaçais la présentation avant d'avoir trouvé le fond.

J'ai eu un très grand choc à l'exposition Simon Hantai à Beaubourg, en 2013. Dans les films, outre le fait qu'il fait craquer avec son corps les nœuds qui, préservant le blanc, traceront le dessin de ses toiles, on le voit tirer sur ces mêmes toiles agrafées aux murs de l'atelier, poser l'échelle sur elles, faire marcher sa petite fille dessus. Son rapport très quotidien et très charnel à son travail, simple, modeste peut-être, sert la profondeur de sa pensée. Certains titres si concrets - les Meuns, les Laissées- noms de lieux ou gestes réels, résonnent avec ma façon de nommer mes œuvres. Je cherche quelque chose de direct, de sobre, de franc, qui n'est en rien une dépréciation de l'œuvre. C'est cet équilibre que je dois trouver. Hantai n'a pas peint, et pratiquement plus parlé de son travail, les vingt dernières années. Ce que je vais dire est probablement une erreur, mais, en voyant côte à côte le naturel de son rapport aux toiles et la perfection de la présentation des œuvres dans l'exposition je me suis demandée s'il n'y avait pas comme un hiatus entre les nécessités du marché ou les conventions de l'institution et sa façon de travailler.

VM : Dans votre atelier sont stockées des œuvres qui ont des formats très différents : des compositions de petites tailles, soigneusement encadrées; des œuvres de grand format réalisées sur papier puis, ensuite, contre-collées ou marouflées pour ne pas qu'elles s'abiment; de très grandes toiles, datant d'une période où le travail sur les blocs rencontre celui sur les pieds, enroulées car non conçues sur un châssis; des travaux sur papier de soie qui ont encore gardé une souplesse malgré la structure sur laquelle vous les avez montés. On note que la réflexion sur ce qui nous fait tenir, interrogation qui traverse votre œuvre, trouve un écho dans le problème de faire tenir la toile, y compris pour l'accrocher dans une galerie ou un musée. Dans votre atelier, tel que je le découvre au moment de cet entretien, deux dessins très synthétiques, réalisés sur un support épais mais souple, destiné normalement à la couture, sont punaisés au mur sans qu'un cadre vienne symboliquement indiquer que le travail est terminé et prêt à être accroché, et donc légitimé par sa présence, dans une galerie. Finalement, l'idée que le cadre, la vitre, le châssis puisse venir clore l'œuvre et signaler un certain aboutissement formel, va à l'encontre de toute votre recherche où la fragilité côtoie de très près la stabilité.

CD : Je disais au début de cet entretien que fond et forme devenaient indissociables au point qu'on ne sait laquelle suscite l'autre. J'ai toujours eu du mal à encadrer; le cadre me semble fixer une limite par décision plus que par nécessité. J'ai besoin qu'une forme ne se fixe que lorsque le mouvement en expansion de mes gestes se tarit, elle se détermine dans l'arrêt d'une énergie. Vous dites: «ce qui nous fait tenir... trouve un écho dans le fait de faire tenir la toile... », c'est parfaitement juste. J'ai toujours peiné, tout au long de ma carrière, pour accrocher mes œuvres : chacune m'a posé un problème d'accrochage. Une toile, La Glissée, a été déterminante : c'était une toile impossible à faire aboutir, conçue peu après mon séjour au Groenland ; alors que j'étais occupée à un autre endroit de mon atelier je l'ai entendue glisser au sol et l'ai vue, seulement retenue dans un angle par quelques punaises. Cette toile à demiaccrochée, à demi tombée, m'a semblé autrement plus juste que ce qu'elle avait été malgré mes efforts pour la terminer. C'est cette expérience qui m'a menée aux installations de cartons par exemple. 
Figure 12. LaGlissée.

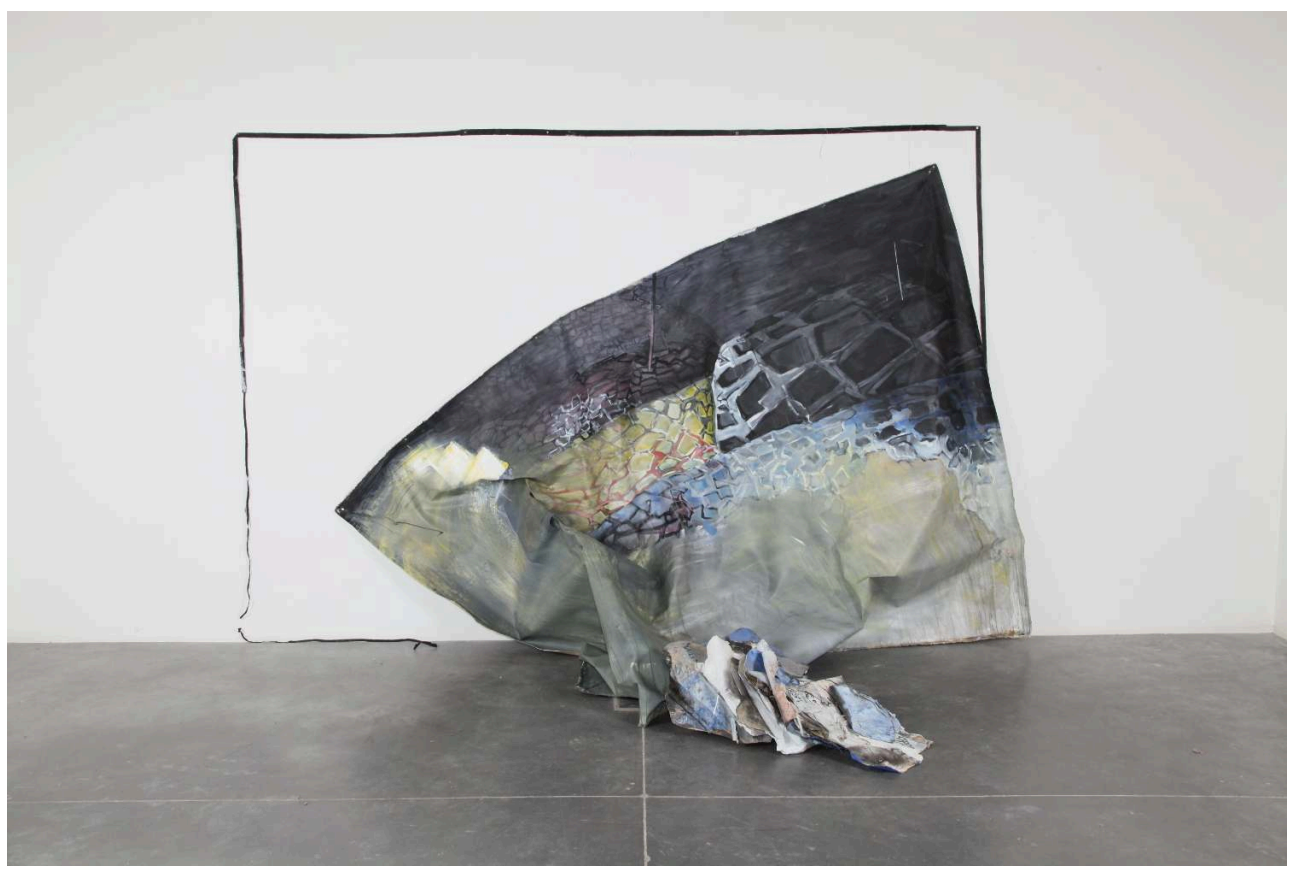

Acrylique sur toile libre, lanière de drap peint en noir, épingles, volume en papier de soie sur grillage. 215/340cm. 2009.

(c) Christine Delbecq.

Figure 13. Dé-Position, installation.

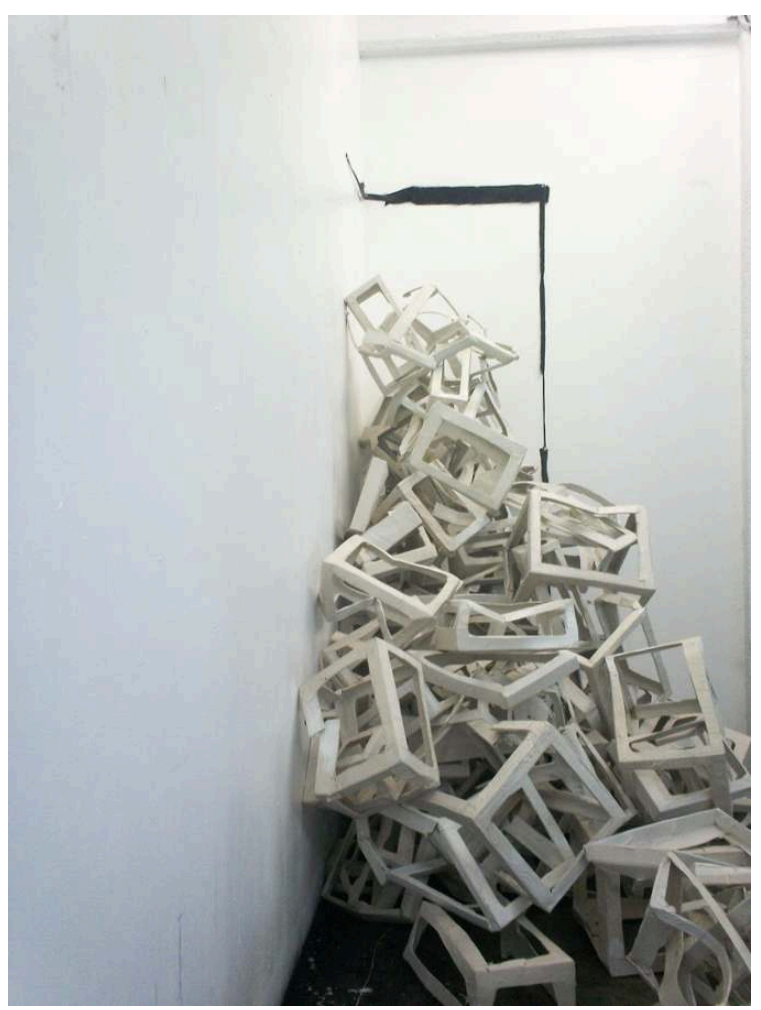

Cartons évidés recouverts de papier journal non imprimé, lanières de drap peint en noir. Configurations variables. Ici dans l'atelier, environ 250/230/.170cm. Depuis 2012.

(C) Christine Delbecq. 
Je suis actuellement en train de réfléchir à des choix définitifs de présentation, en reprenant des travaux terminés mais dont l'accrochage n'est pas encore entièrement juste. Je ne pouvais travailler sur châssis, ni encadrer ; j'accrochais mes grandes toiles $(350 / 250 \mathrm{~cm})$ sur un mur, au ras du sol, comme si elles étaient debout, j'accroche (les épingles ne resteront peut-être pas) des supports épais et souples de façon à ce que leur tenue semble naturelle; je cherche une tenue naturelle des choses. Si j'ai souffert du peu de visibilité de mon travail, j'ai, sans doute, brouillé les pistes, fait en sorte (instinctivement, à mon corps défendant) de préserver l'évolution de tout ce travail en le rendant difficile d'accès, mal définissable. Il me semble cependant que j'avance lentement vers quelque chose qui pourrait se rendre visible sans perdre cette fragilité en mouvement.

Figure 14. LesSouples, série.

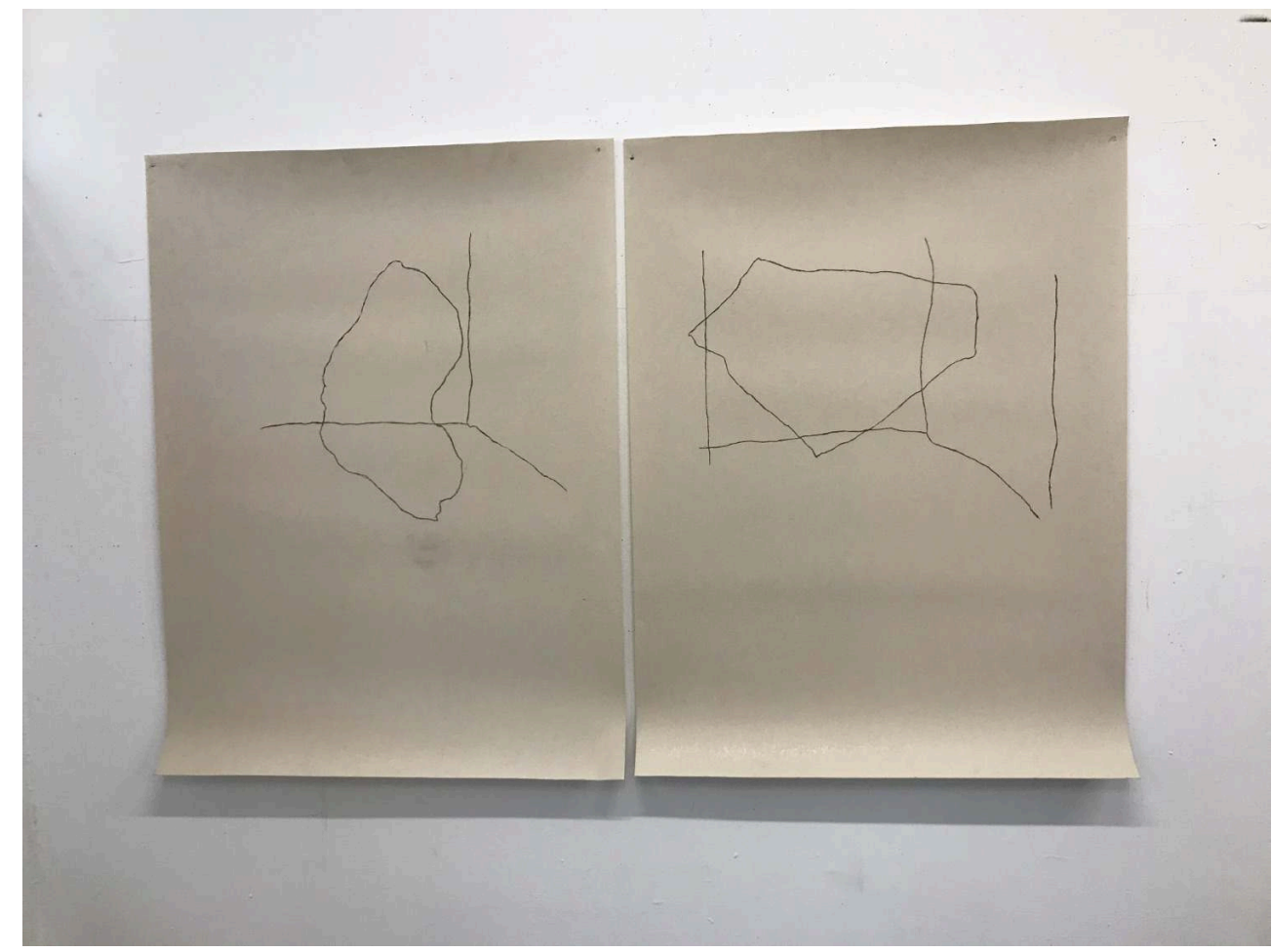

Crayon gras sur tissu thermocollant. Deux fois 90/120cm. 2019/21.

(C) Christine Delbecq.

VM : Je comprends ce souci de maintenir quelque chose de la dimension inchoative de la création, de préserver la trace du magma qui insuffle l'énergie de la mise en forme initiale. La beauté est-elle pour vous dans le désordre? Vous aimez parler de la création comme force magmatique.

CD : Oui, mais magma n'est pas désordre. Magma m'évoque davantage la force d'un mouvement interne qui déterminera la forme, ou l'absence de forme, d'importance équivalente dans mon travail. Le poète Ludovic Degroote dit souvent qu'une vie n'a sa forme propre que lorsque la mort en place la seconde borne. C'est peut-être cette idée, ou cette peur, qui forment et informent mon travail. 
Figure 15a, b, c, d, e, f. Les SoulèvErts, installation et peintures agrafées.

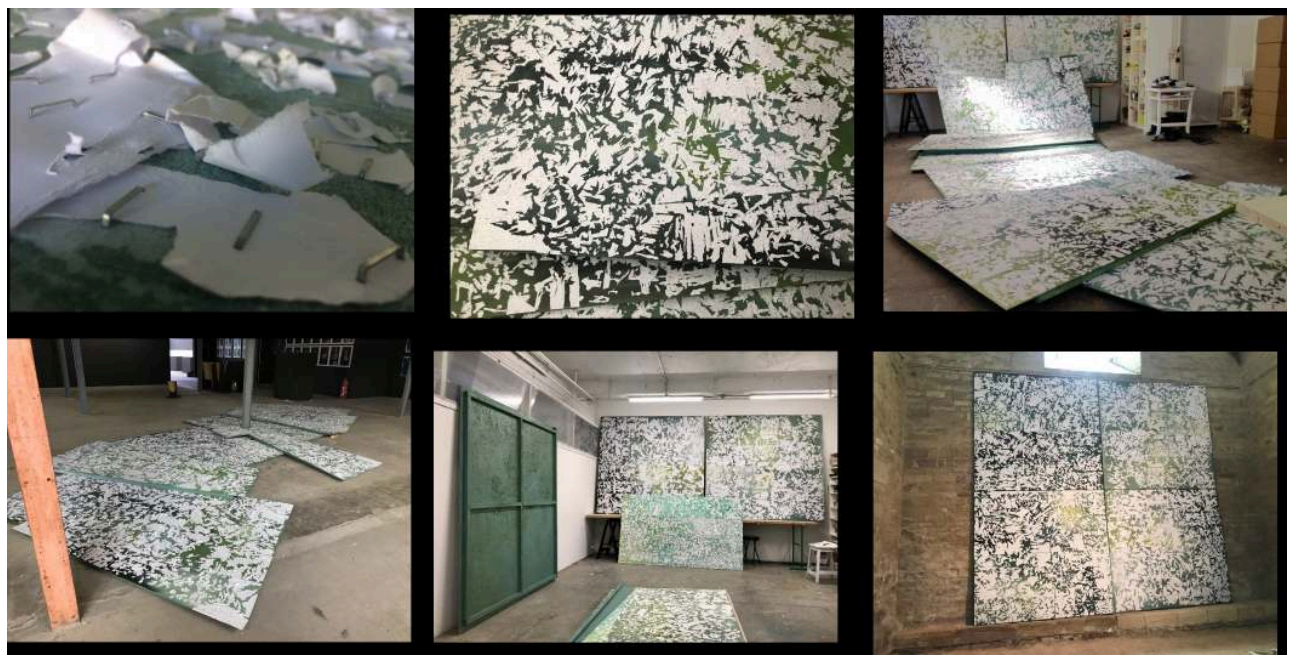

Papier machine, agrafes, contreplaqué peint en verts, filins, moteur. Détails. Dans l'atelier. La Nouvelle Laurentine à Châteauvillain. Eglise Saint-Philibert de Dijon. Dimensions et configurations variables. Depuis 2018.

(C) Christine Delbecq.

Dans Les SoulèvErts par exemple, la version suspendue à plat se compose de trapèzes plus ou moins aléatoires qu'un agencement adapté au lieu d'exposition structure ; les versions murales sont contenues dans des carrés ou des rectangles qui les rendent juxtaposables à l'infini, donc en expansion possible. Les ChaosCarton sont formés de centaines de cellules structurées : parallélépipèdes de carton évidés puis recouverts de papier journal non imprimé, déformés parfois au moment où la colle les rend momentanément mous. Et je vais choisir de les accumuler en ordre ou en chaos, chaque option ayant son sens. 
Figure 16. ChaosCarton, installation, église Saint-Philibert de Dijon, juillet 2021.

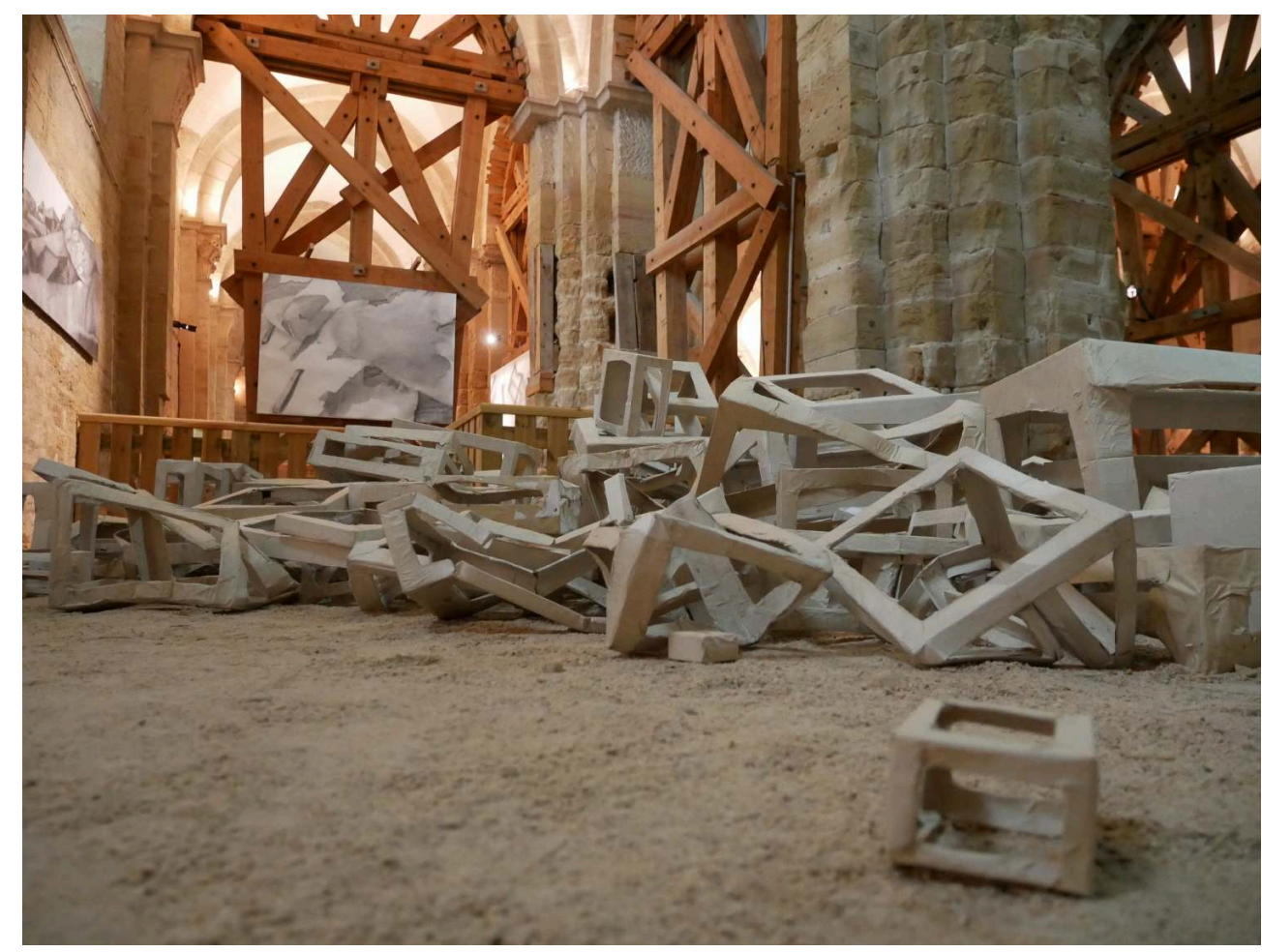

Ici environ 700/600/90cm.

(c) Christine Delbecq.

Si vous regardez les PenchéFils, les fils tendus structurent l'espace alors que les éléments assemblés sont déchirés de façon aléatoire, puis assemblés de façon sensible. Je crois que c'est le mélange - ou la tension - entre les forces d'organisation et d'expansion qui me procure le sentiment de beauté, parce que de justesse.

vм : Beaucoup de vos réalisations donnent l'impression de résulter d'une propagation, d'une dissémination ou d'un déploiement. Les œuvres sont immobiles mais laissent imaginer un mouvement.

CD : Oui c'est exactement ça. Elles ont d'ailleurs longtemps été immobiles, mais frémissantes j'espère. J'ai récemment pu faire motoriser par Patrice Ferrasse, également plasticien, la version suspendue des SoulèvErts : il a trouvé un balancement presque imperceptible et discontinu, qui est exactement ce que je voulais. J'ai tourné quelques très courtes vidéos - Les fragiles qui résistent, Respir - où, grâce à un ventilateur, mes bouts de papier déchirés, ou des feuilles A4 épinglées au mur, sont mis en mouvement juste un instant, un souffle qui ouvre une petite histoire singulière, et que je présente un peu distanciée de l'installation d'où elles sont tirées. J'aime que ce que je fais échappe à une interprétation unique, que tous nous puissions le nourrir de nos expériences de vie ou nous laisser emmener. D'une certaine façon, ma pratique du dessin contient ce même mouvement interne : le fait d'agrandir des détails minuscules entraîne des milliers de coups de crayon de papier juxtaposés dont l'assemblage finit par faire la forme, ou la dissoudre : je suis très attachée à la notion de flou, aimant à photographier tellement près qu'on perd la forme.

vм : Vous présentez le livre Chaos Carton, conçu en 2017, ainsi : "Ce recueil plie et déplie, au propre et au figuré, ce qui me fascine dans la figure du parallélépipède évidé. Aussi solide que déformable, elle se prête à de multiples mises en scène pour nous parler de 
nous » (Delbecq 2017, n.p.). L'ouvrage, qui contient un jeu de 15 cartes avec des fragments de votre collage photographique, est un livre participatif qui fait du lecteur un co-créateur du sens. Ludovic Degroote, qui a rédigé le texte en réponse à votre travail sur les blocs, écrit : "Le désordre du corps se tient comme il peut dans ses intérieurs. Matière ouverte et fermée, il semble parfois se recouvrir d'un autre corps qui en distribuerait autrement les vides et les pleins, donnant alors à son propre espace la possibilité de se déplacer. » (n. p.) Dans plusieurs projets, vous avez eu le souci de laisser le spectateur compléter ou altérer une proposition grâce à des choix de formats ou dispositifs spécifiques, notamment des objets qui se déplient ou se déroulent.

CD : Dans son beau texte Ludovic Degroote introduit la notion de déplacement, qui convient aussi bien pour ce qui se passe à l'extérieur qu'à l'intérieur, et me rejoint fortement: bouger pour voir autrement, pour s'agrandir, même si c'est infime. Ou parce que c'est infime. J'ai écrit frémissement au début de notre entretien : cette invitation à un mouvement, une palpitation, que je fais au regardeur - spect-acteur a écrit Maryse Ginet pour présenter l'exposition On a penché l'horizon, existe quelque part dans mes travaux, toujours ; elle existe dans " ce qui arrive aux matériaux », par encollage, déformation, chauffage, déchirage, tout ceci altère en effet; elle existe dans la présentation ensuite. Le Coussin d'airbes (airbes !) peut se balancer ; les papiers agrafés frémissent sous le ventilateur; les feuillets d'herbe peuvent s'envoler lorsque quelqu'un passe devant leurs piles. J'invite les visiteurs à les manipuler délicatement. Ils peuvent longer les grandes peintures au sol, faire bouger les plaques suspendues des SoulèvErts. Comme dans les Petits rouges, ce qui est immobile capte un mouvement : un geste déchiré, l'élan entre deux corps. Le spect-acteur peut déplier les pages de ChaosCarton comme il peut passer sous la traîne de La grande mariée. Le titre de l'exposition On a penché l'horizon, c'était bien l'idée du déplacement, ce que propose l'art je crois : parfois un si petit pas de côté, mais tout est transformé. 
Figure 17a. La Balançoire à feuillets d'herbe.

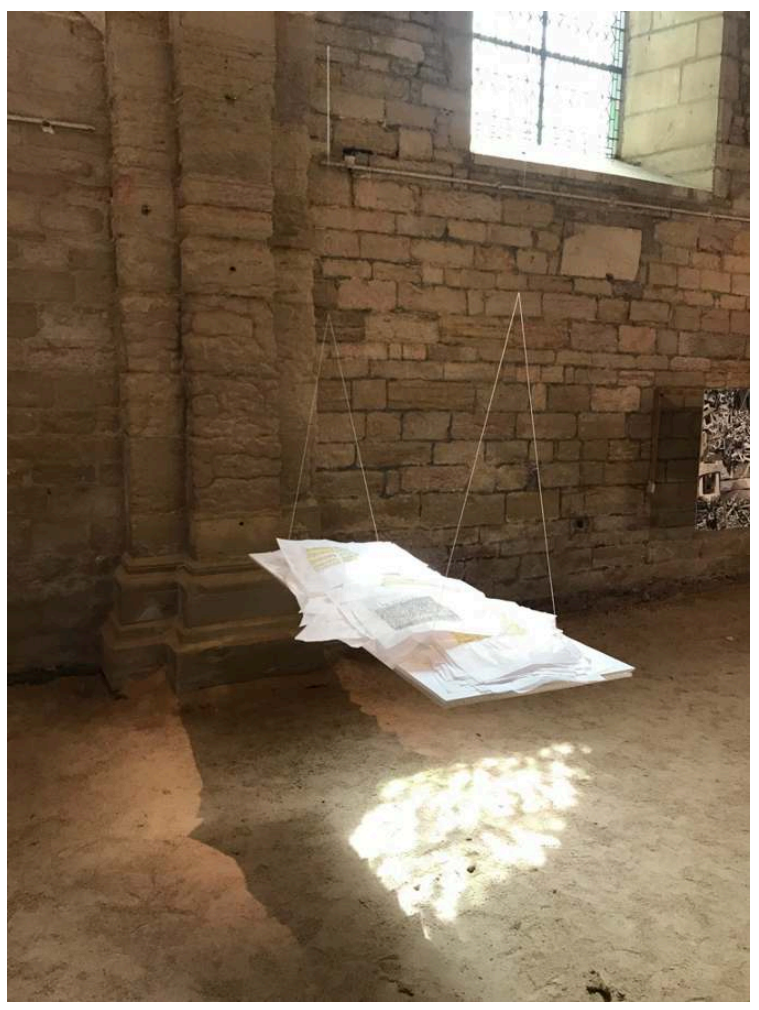

350 feuillets de papier de soie, carton plume, polycarbonate, cordelette. 160/65/25cm. 2020/2021. Église Saint-Philibert de Dijon, juillet 2021.

(c) Christine Delbecq. 
Figure 17b. 350 Feuillets d'herbe.

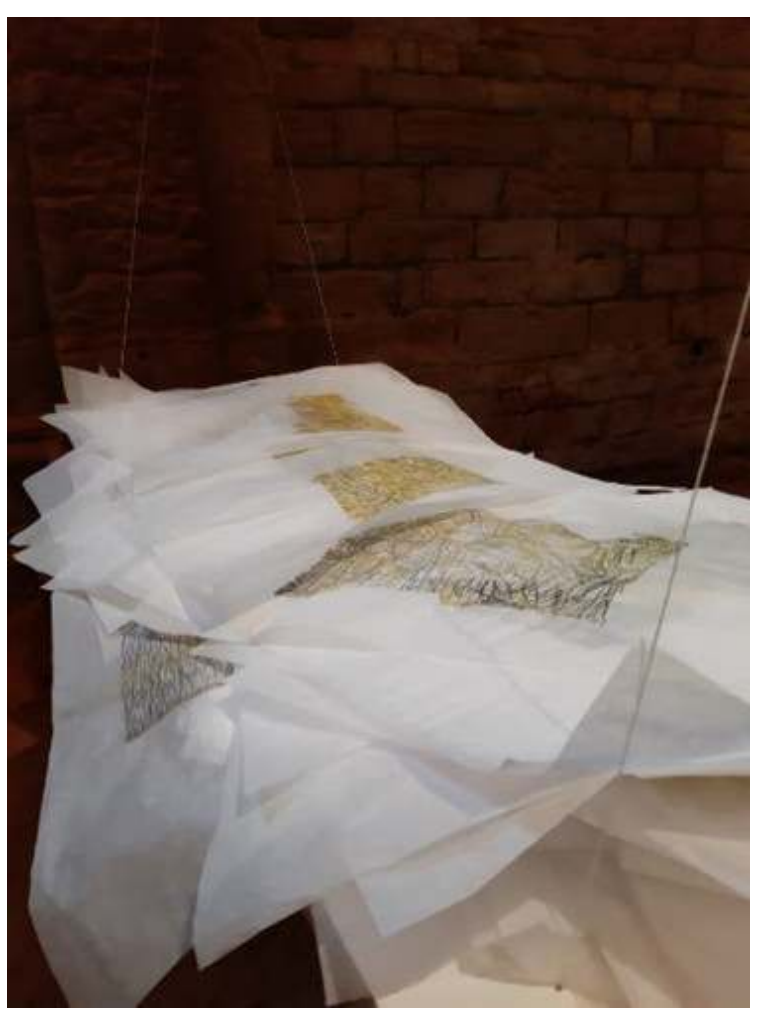

Crayon de papier et feutre posca jaune sur papier de soie marouflé sur papier de soie.2020/21. (C) Christine Delbecq. 
Figure 17c. Coussin d'airbes.

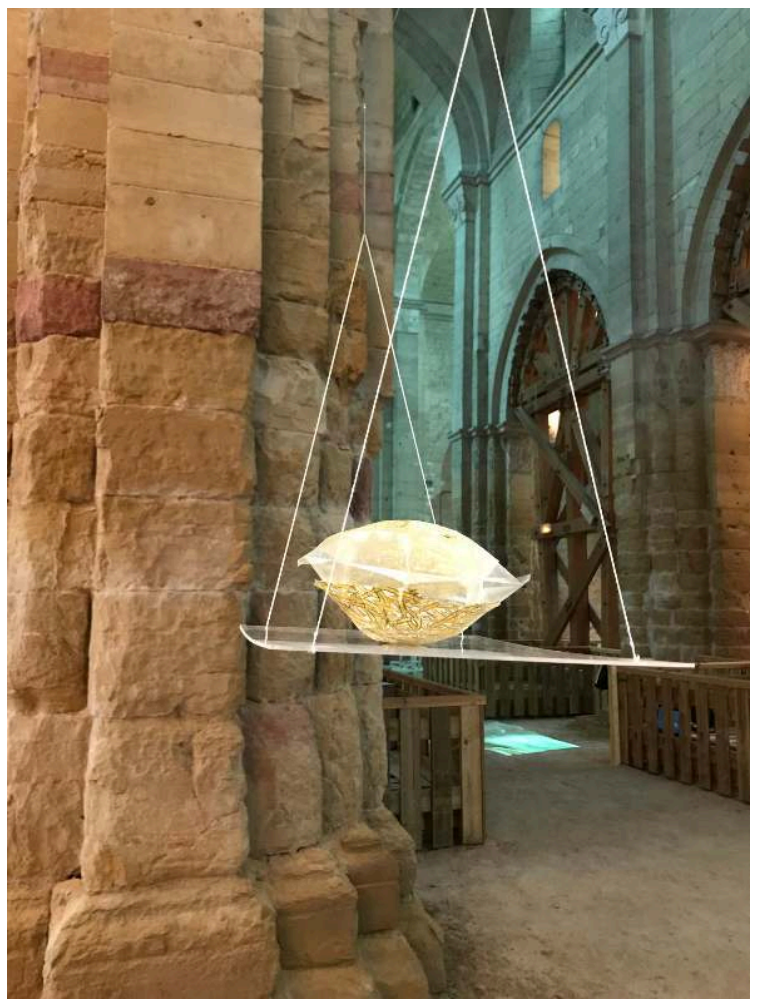

Coussin de plastique gonflé, papier de soie, crayon de papier, feutre posca jaune, plexiglas, fil à coudre. 40/30/25cm. 2020.

(c) Christine Delbecq.

VM : J'aimerais revenir sur la place du dessin dans votre travail. La pratique classique consiste à réaliser des croquis ou dessins préparatoires qui servent de base à une œuvre plus grande. Le dessin est souvent un projet. Mais votre démarche est presque inverse: vous revenez au dessin comme ultime déploiement d'une œuvre plus grande. C'est intrigant. II y a une circulation singulière dans vos œuvres, une transmutation des formes, comme vous le dites, une plasticité qui privilégie la transformation et non la stabilité. Je pense là à ce que la philosophe Catherine Malabou dit des mutations, principes du vivant, qui n'indiquent pas que l'on progresse ou que l'on améliore un dispositif, mais que l'on s'ouvre à ses altérations et ses métamorphoses. Vous aviez suspendu, il y a longtemps, des rubans noirs dans votre atelier, araignées de tissu qui occupaient l'espace de façon informe, que vous avez recyclés dans des sculptures mais qui réapparaissent dans bien des réalisations: des dessins au Groenland où le sol devient un ruban ou un tracé; des peintures très graphiques; des papiers froissés au dos desquels court un ruban noir comme une colonne vertébrale; des filins qui affirment leur fragilité. Dans un texte écrit à l'occasion de l'exposition Voyages en art'chéologie, Monique Jannet dit que votre œuvre est « en intégralité reprise, coupée, partagée, redécoupée, décalée... » (Delbecq 2001, 9). Les variations de format sont des translations plus que des conversions. Malgré l'impression d'éclectisme que l'on a en visitant votre réserve, il existe un vrai fil conducteur dans votre travail.

CD : J'ai toujours eu, comme la plupart des sculpteurs, une pratique de dessins préparatoires, des dessins-maquettes. C'est relativement récemment que je suis arrivée à ces dessins pour le dessin. Je fais à présent des dessins très grands (200/150cm environ), au crayon de papier; j'agrandis des détails minuscules photographiés de très près, quitte à ce qu'ils soient flous, et souvent, au bout de ce travail de dessin, le chantier va vers sa fin (de réalisation, pas de présentation). Ils 
sont une mise en exergue de sensations précises qui m'importent, alors qu'elles sont diluées dans l'espace de l'installation originelle. Installations que j'appelle aussi matrices, tant elles m'ouvrent un champ de déclinaisons possibles. Le dessin est un lieu de transmutation (quand par exemple les bouts de papiers agrafés deviennent par le dessin des paysages arctiques), mais aussi un espace d'expérience en soi, par ces ondulations en noir et blanc qui outrepassent les images repérables. C'est bien un cycle, qui relie la "chose » concrète à son exploitation. (Il y a une justesse du mot chose, pour dire la simplicité et la tangibilité d'une œuvre, posée dans le monde.) Lorsqu'à partir de ces choses j'en viens au dessin, ouvrant par l'agrandissement d'autres lectures, les dessins aussi deviennent des choses.

Figure 18. SoulèvErtsHauts, dessin.

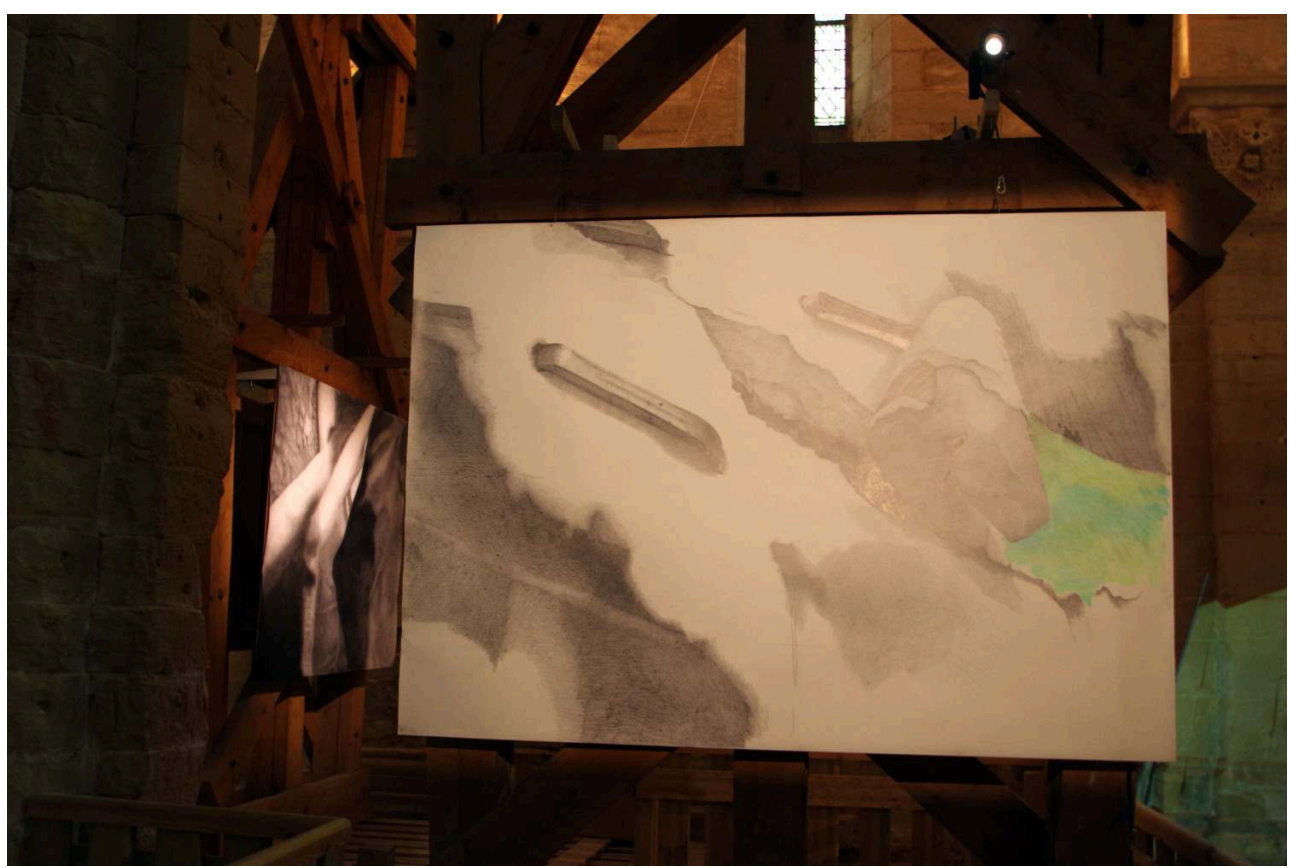

Crayon de papier et craie verte sur papier canson. 200/150cm. 2020.

(c) Christine Delbecq. 
Figure 19. Dé-Position, installation.

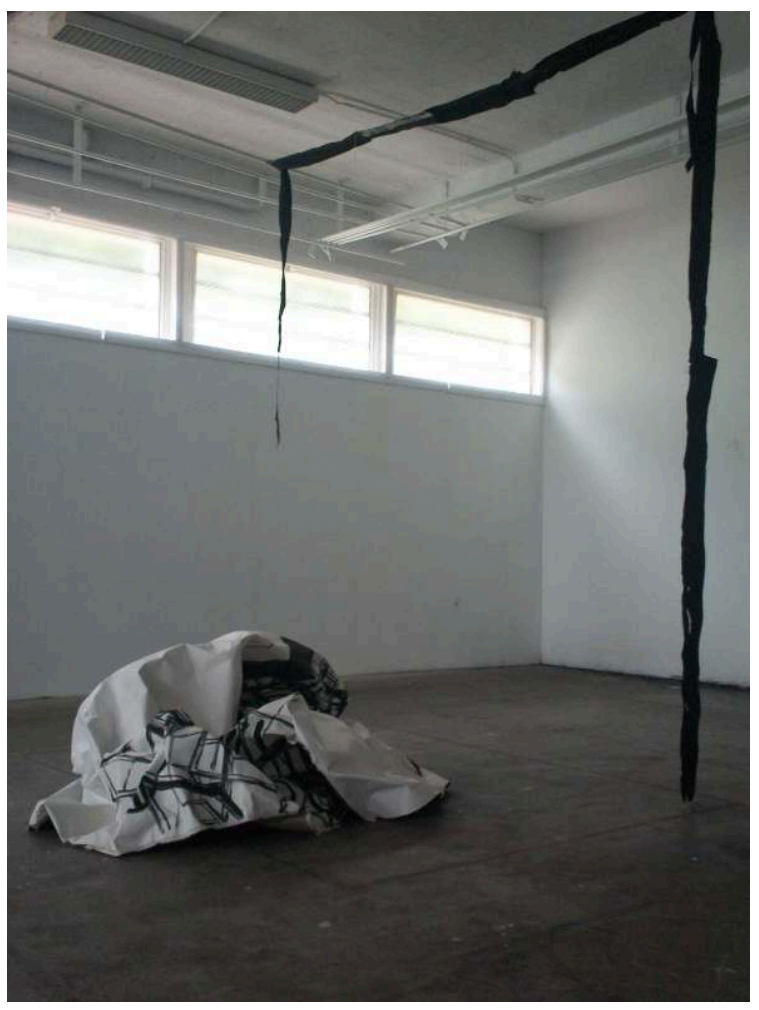

Toile à peindre, lanière de drap peint en noir. Configurations et dimensions variables. Ici dans l'atelier, environ 330/300/120cm. 2014.

(C) Christine Delbecq 
Figure 20. CarréLanières, dessin.

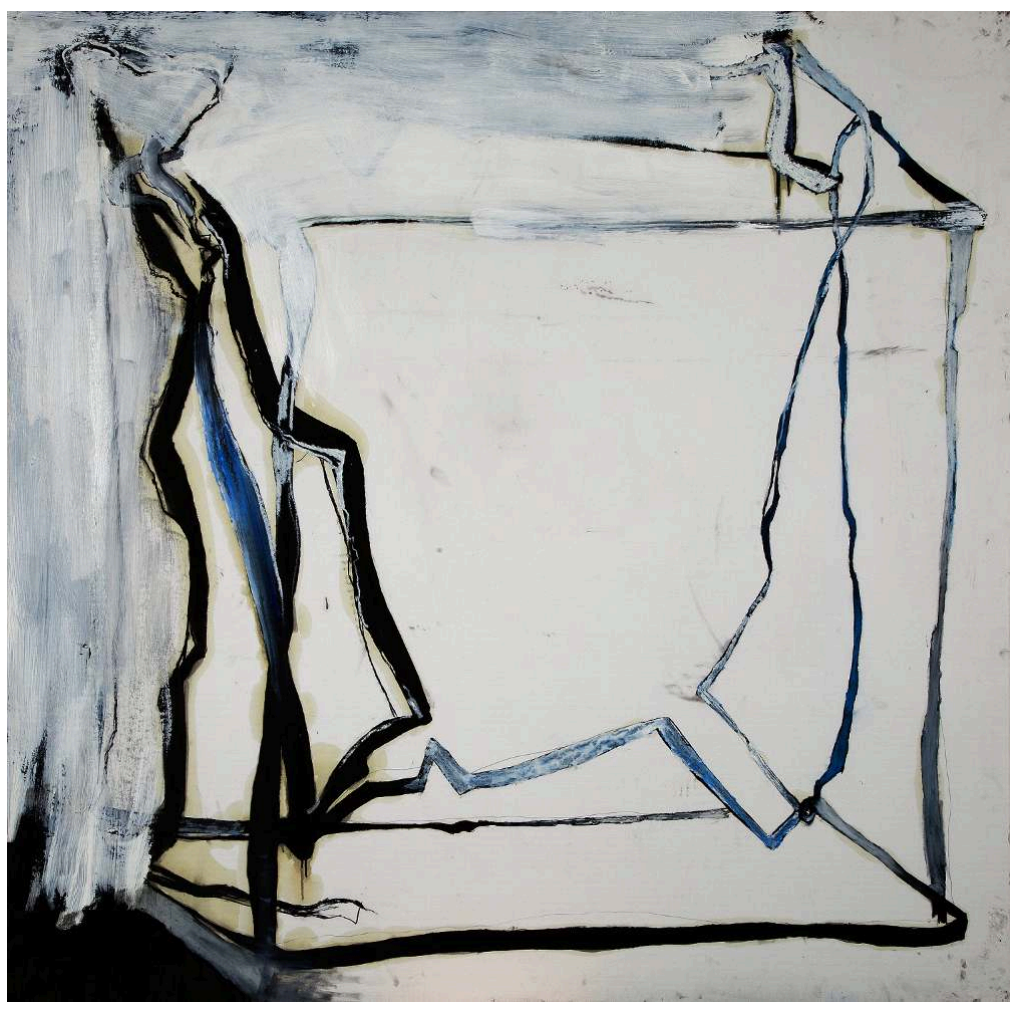

Craie carrée noire et huile sur papier canson marouflé sur polycarbonate. 120/120cm. 2010/12. (C) Christine Delbecq. 
Figure 21. En suspens, dessin.

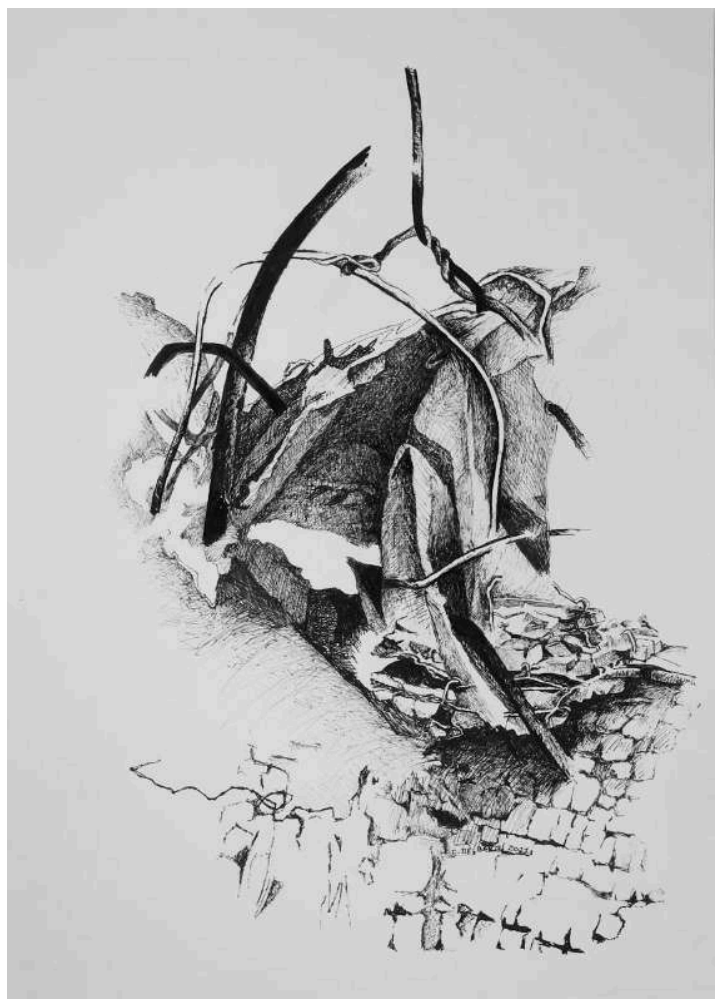

Feutre noir sur papier bristol. 30/40cm. 2010.

(c) Christine Delbecq. 


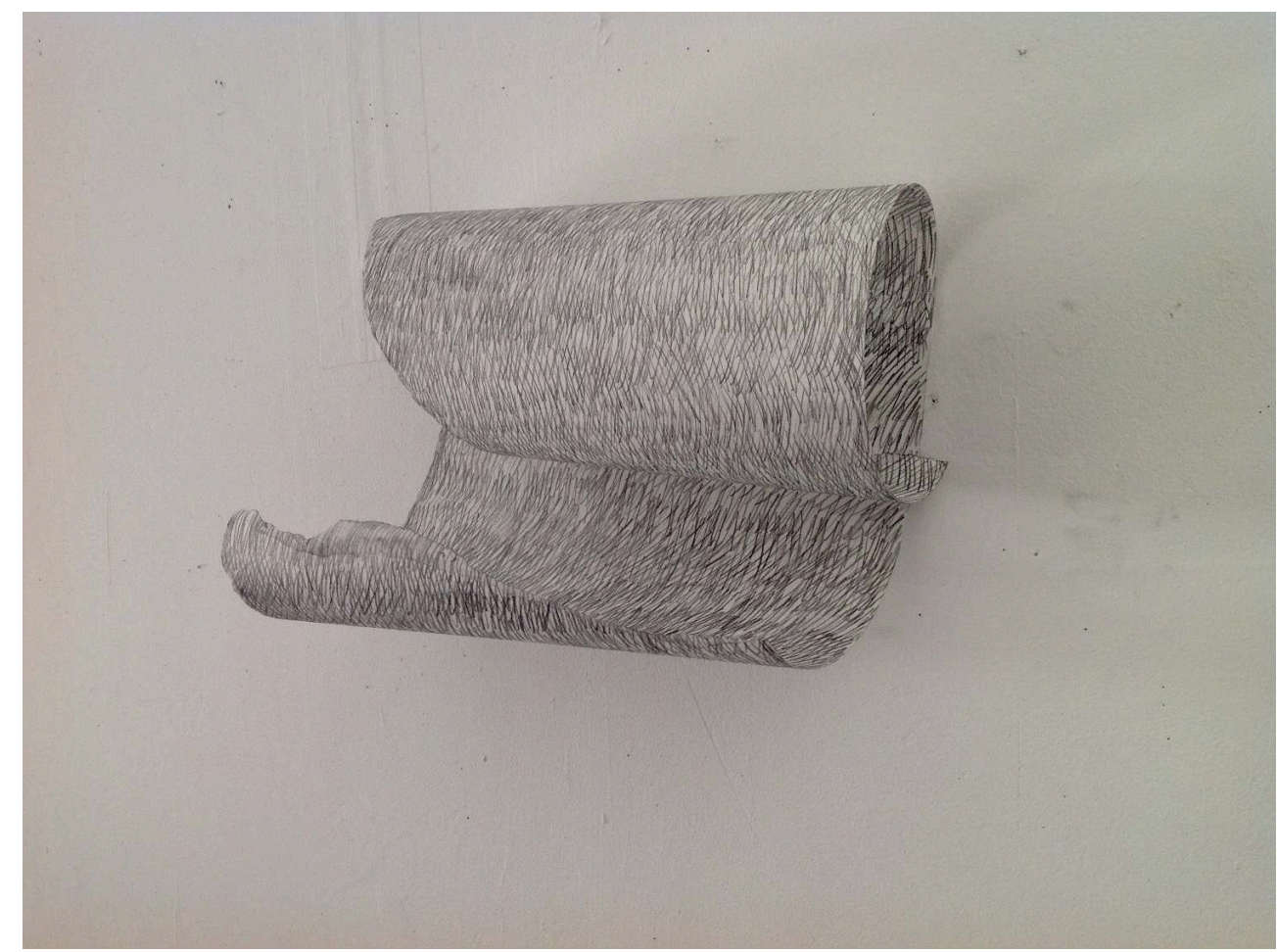

Crayon de papier sur papier canson. 36/30/45cm. 2019.

(C) Christine Delbecq.

vм : Vous êtes intervenue dans trois lieux très différents de la métropole dijonnaise : les salles du musée archéologique où il a fallu intercaler vos œuvres entre les vitrines ; la MSH, un espace non-scénographié, mais imposant malgré tout des contraintes spatiales; puis l'église Saint-Philibert où vous avez installé «On a penché l'horizon ». Chacun de ces lieux vous a forcée à réfléchir au format non seulement de l'œuvre mais aussi de l'exposition. Dans le cas du musée archéologique, quel dialogue avez-vous cherché à établir avec le lieu et ses collections?

CD : L'exposition Voyage en ArtChéologie est née d'une belle rencontre avec MoniqueAnne Jannet, alors directrice du musée archéologique, décédée récemment. Je peignais à ce moment-là des parties de mon corps, les pieds en particulier. Monique Jannet avait travaillé sur les ex-votos trouvés dans les sources de la Seine, qui sont présentés au musée. Elle a décelé un parallèle entre ma façon de répertorier les éléments de mon corps (le care dont vous parliez ) et l'appel à la guérison dont les malades investissaient les sculptures en pierre des organes malades, petites sculptures qu'ils jetaient dans les sources de la Seine. Après une visite dans mon atelier, elle m'a dit : «tu peux prendre tout le musée, installe toi ». Dans la grande salle du premier étage, j'ai suspendu dans le vide les grandes toiles libres des pieds et blocs, et nous avons utilisé une magnifique structure métallique en demi-cercle pour suspendre sur plexiglas les dizaines de dessins que j'avais réalisés l'année précédente lors d'une résidence au musée archéologique de Baïa Mare, en Roumanie. Je me suis intercalée, glissée de multiples manières dans les collections, entre deux pierres tombales, sous les vitrines, au milieu des stèles de présentation des pièces archéologiques, avec des dessins, peintures, petites sculptures qui mêlaient mes pieds et mes pierres à des ex-voto sortis des réserves du musée. Chaque présentation découlait d'une présentation du musée, ou d'un morceau de mur, ou d'une place dans 
l'espace. C'était une expérience formidable: j'avais un budget, une équipe, la confiance de Monique-Anne Jannet. Aujourd'hui je pense que l'ensemble était sans doute difficile à lire, trop éclectique, moins radical que ce qui s'est élaboré peu à peu. Mais il a été un jalon fort dans mon plaisir et mon intérêt à dialoguer avec un lieu.

vM : Vous avez été sollicitée pour intervenir à la MSH et vous avez fait le choix d'une intervention de grande taille. Comment ce choix de format s'est-il imposé ?

CD : Le lien avec la MSH s'est fait grâce à Sophie Desseigne, alors directrice des bibliothèques universitaires, également directrice des éditions p.i.sage int.érieur . Elle a collaboré avec le poète Yves-Jacques Bouin, avec qui j'avais déjà travaillé plusieurs fois. Ils m'ont proposé d'accompagner graphiquement le premier recueil de la poète Myriam Eck, Mains suivi de Sonder le vide, trouvant une résonance certaine entre nos obsessions, et de prolonger cette rencontre plastique dans le cadre du programme "Un artiste, un chercheur » initié par la MSH. Nous avons ainsi donné une conférence à trois, Myriam Eck, Pierre Ancet, philosophe, et moi, à partir d'une dizaine de mots issus du recueil de Myriam et dont chacun de nous offrait l'interprétation, ou l'usage concret, qu'il en avait dans sa propre pratique.

L'espace d'exposition qui m'a été proposé est aussi salle de colloques, assez ingrate hormis ses belles proportions et l'immense baie vitrée. Les murs sont recouverts de panneaux d'aluminium perforés, le sol dallé, les rangées de spots au plafonds insérées dans des caissons noirs permettant de faire des lignes d'œuvres à regarder : je n'en ai eu aucune envie, ne disposant par ailleurs pas de formats moyens, n'ayant d'appétence que pour les tout petits ou très grands formats. Le texte de Myriam m'ouvrait un « dans ", "à l'intérieur » d'une histoire dont elle ne donne aucun détail concret; elle dit un face à face, un corps à corps, dans lesquels chacun de nous peut se projeter. Cette façon de faire est très proche de ce qu'est devenu mon travail : dans un entretien récent avec Chantal Nardin - directrice de la bibliothèque de SaintApollinaire - je dis « je ne vous montre pas quand ni où ni avec qui, mais je fais chute, et on a tous chuté, je fais en suspens, et on a tous été en suspens, etc. ». J'ai décidé de coudre une immense bâche de plastique translucide, suspendue comme un hamac géant dans lequel j'ai jeté deux de mes petits parallélépipèdes blancs. Je les avais lancés de façon à ce qu'en entrant dans la salle on ne les voit pas, on ne voyait que les plissés souples de la bâche et ses reflets sur le sol dallé, il fallait faire le tour de l'œuvre pour en percevoir le sens. L'œuvre suspendue, centrale, était accompagnée de deux paysages du temps, les Chambres d'échos, accumulation-organisation des détails photographiés à l'intérieur de mes bâches et cartons. La lumière de la baie vitrée dessinait les reflets au sol et modifiait constamment l'intensité des dégradés de ce que j'ai appelé Dans le grand blanc. Dans cette salle disparate (on le voit sur les photos) alors que sur place, l'œil fait le tri, hiérarchise) j'ai centré la vision sur cette grande masse blanche. 
Figure 23a, b. DansLeGrandBlanc, installation et détail.

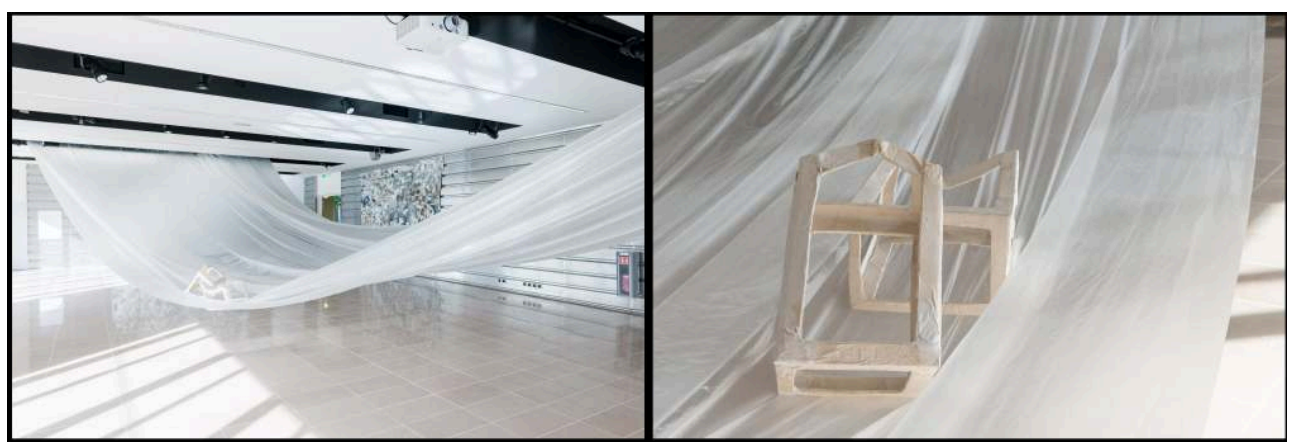

Bâches plastiques cousues, cartons évidés recouverts de papier journal non imprimé. Exposition Maison des Sciences de l'Homme, campus universitaire de Dijon, 2016. 1500/800 cm.

(c) Christine Delbecq.

Mon travail à la MSH marque le glissement de la notion d'exposition à celle d'installation, ou peut-être plus justement, à celle de mise en forme d'un univers dans lequel les visiteurs puissent entrer, qui nait de la résonance entre les œuvres. J'avais suspendu, au fond de la salle, une rangée de panneaux de PVC blanc, tout en hauteur, sur lesquels j'avais accroché 75 petits tableaux rouges, des collages de papiers qui étaient autant de projets d'installations avec une bâche et des filins, en écho avec la grande bâche centrale. Leur alignement faisait écran à l'entassement des chaises et tables servant pour les colloques. Le lendemain du vernissage, j'ai retourné tous ces panneaux du côté blanc, ne laissant qu'un minuscule collage rouge, parce que l'ensemble me renvoyait trop à une suite d'œuvres, pas assez à la circulation entre les trois projets présentés. De fait, de nombreuses personnes m'ont parlé depuis de leur expérience d'immersion à l'intérieur du blanc rebondissant de la bâche aux panneaux photographiques. Ça aurait été moins net si j'avais laissé les Petits rouges.

vM : Nous nous sommes rencontrées lors de votre dernière exposition dans l'église SaintPhilibert, un lieu qui porte des stigmates et qui, nécessairement, informe ce qui est exposé. Au centre de l'exposition, vous aviez placé, sur une feuille de plexiglas tenue par deux fils, un petit oreiller de plastique recouvert de papier. Cette création attirait l'attention sur des préoccupations qui sont les vôtres depuis toujours : la recherche d'équilibre, la vulnérabilité, la fragilité des liens. J'ai été très émue par le dialogue établi entre cette œuvre et le lieu.

CD : Merci. J'ai moi-même été très émue par le lieu. J'en ai entendu parler pendant vingt ans avant de pouvoir y entrer, parce que je suis arrivée à Dijon au moment où il était fermé au public. Et ma première visite a été à la hauteur de mon imaginaire. Pendant l'exposition j'ai rencontré plusieurs érudits et historiens qui m'ont fourni des informations étonnantes renforçant le double sentiment de puissance et de précarité que nous renvoie ce lieu. Non seulement ces deux mots - puissance, fragilité - sont essentiels dans mes recherches, mais l'idée du paradoxe y est sans doute centrale. Le contraste. Le balancement. L'équilibre et le déséquilibre. J'ai essayé d'organiser toute l'exposition par ricochets, en triangulant les trois thèmes de travail retenus (les ChaosCarton, les papiers déchirés, l'herbe), trois façons pour les œuvres d'être posées (à terre, en suspens, verticales), trois modes de construction (en volume, à plat, en mouvement). Je me suis inscrite dans l'espace de façon à ce qu'à la fois le lieu paraisse presque vide quand on entrait et que de plus en plus de propositions se découvrent quand on circulait. 
Figure 24. ChaosCarton, installation.

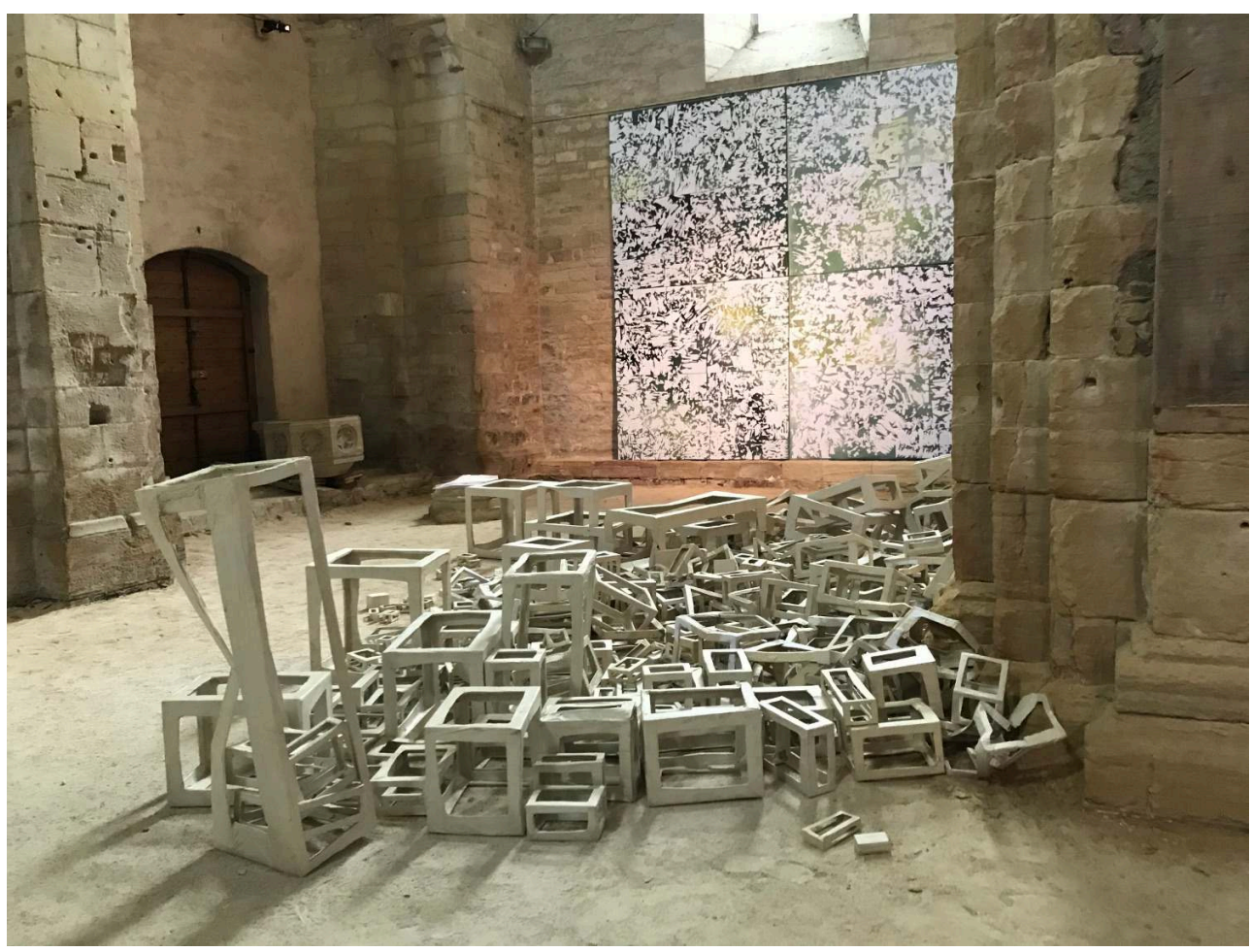

Depuis 2013. Configurations variables. Eglise Saint-Philibert de Dijon, juillet 2021. Environ $700 / 600 / 90 \mathrm{~cm}$. Au fond, les SoulèvErtsDebout,peintures agrafées, 4 fois 200/200cm.

(c) Christine Delbecq.

Ce «Coussin d'airbes » dont vous parlez, c'est un échappement : une grande part de mon travail est très longue à réaliser. En ricochet avec ce temps long, surgissent par déclics des émanations, ultra rapides à réaliser. Elles sont comme la jonction, dans un résumé ouvrant une nouvelle piste, entre plusieurs chantiers en cours. J'appelle chantier les cycles (entre huit et quinze ans) de travaux autour d'une même notion. Ce petit coussin de plastique empli d'air, recouvert de papier de soie griffé de traits inspirés des photos d'herbes prises au ras des pieds, est posé en balançoire sur une plaque de plexiglas suspendue par du fil à coudre; il a fait se rencontrer le travail des soulèvements de papier et celui sur l'herbe. Et les balançoires sont un motif récurrent chez moi. 
Figure 25. Le coussin d'airbes, suspension.

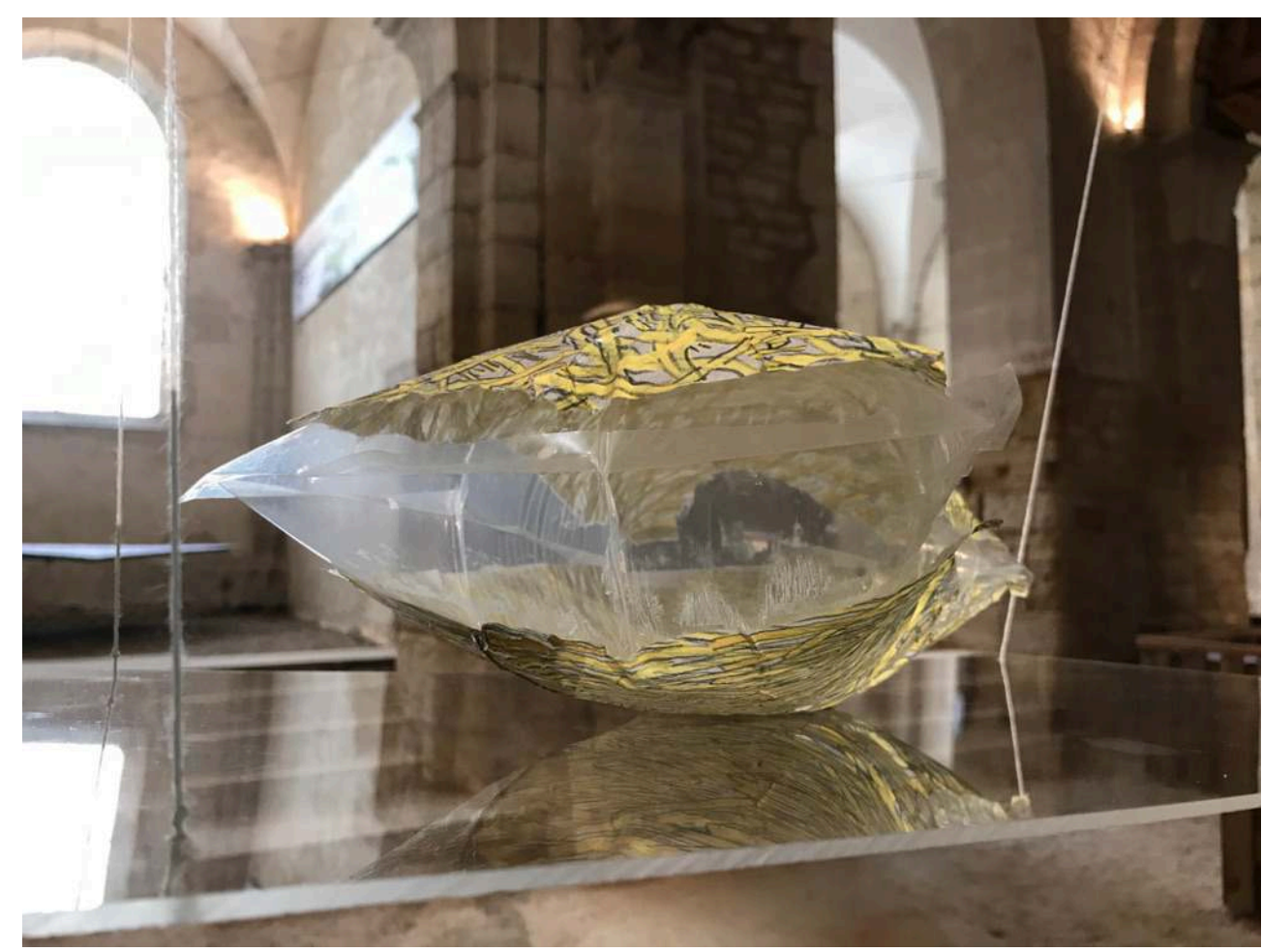

Coussin gonflable, papier de soie, crayon de papier, plexiglas, fil à coudre. 30/40/25cm. 2020.

(c) Christine Delbecq.

Certaines personnes m'ont dit qu'il n'y aurait pu avoir que lui dans Saint-Philibert, tant sa présence pourtant minuscule était forte dans l'espace. Mais j'avais besoin d'un ensemble. Je savais depuis le début qu'il était un élément essentiel de mon projet, et je ne pouvais pas déterminer sa place sur les plans. Nous avons monté, avec mon extraordinaire équipe d'assistants bénévoles, toutes les grandes pièces. Et à la fin, quelqu'un s'est baladé dans l'espace avec le Coussin d'airbes, comme avec trois autres minuscules éléments de l'exposition, jusqu'à ce que je dise : stop, on arrête, c'est là.

Claude Martel, qui m'avait exposée à la Galerie La Source de Fontaine-les- Dijon il y a très longtemps, avait écrit ceci pour cette exposition, qui s'appelait Entre deux, entre plusieurs : "L'accrochage est une composante majeure du processus de création. L'œuvre, pour être finie, doit être exposée. Le mur, l'espace environnant, deviennent surface picturale sur laquelle est collée la composition artistique. Ils font partie de l'œuvre. Le spectateur est amené à l'intérieur de cet espace et à son tour devient partie intégrante de l'œuvre, ce qui annule la distinction entre espace réel et espace pictural ${ }^{3}$.»

On m'a tellement parlé de la résonance entre mon travail et le lieu, formellement et dans le sens, que j'ai fini par m'inquiéter, me demandant ce qui resterait de ce travail sans le lieu. A surgi le désir de pouvoir exposer ensuite dans un lieu très blanc, très neutre, et de voir comment je réagirais à ce nouvel espace. Je pense que ce serait complètement différent, que ça me ferait peut-être insister sur d'autres éléments de mon travail ; il me semble cependant qu'à chaque lieu je trouverai une proposition qui lie l'un et l'autre.

vм : Depuis plusieurs années, les artistes font se rencontrer les pratiques de l'installation et de l'exposition, devenant créateurs et curateurs. Dans le cas de On a penché l'horizon, vous 
avez réfléchi à ce qui distingue une exposition d'une installation, deux formats différents. Si vous aviez à remonter cette exposition, opteriez-vous pour quelque chose qui s'apparenterait davantage à une installation, c'est-à-dire une proposition où le lien entre les objets exposés est plus fort et où la proposition se perçoit comme un tout?

CD : Oui, et non. Je pense que je continue à approfondir cette voie. J'en ai parlé plus haut, je ne voulais pas faire une exposition comme suite bien agencée de travaux. Je voulais proposer une immersion dans un monde. Je voulais respecter Saint-Philibert, je sentais les échos profonds entre le lieu et mes préoccupations, et je voulais qu'on sente ce qui lie mes travaux apparemment disparates. La question que vous me posez, j'y ai énormément réfléchi pendant tout le temps que j'ai passé dans le lieu en juillet, et depuis. J'ai eu plus d'une idée, il pourrait n'y avoir qu'une œuvre, minuscule, énorme. J'ai vu l'exposition suivante, celle de Valérie Couteron, qui reprenait l'idée de notre salon-projection pour le film d'entretien avec Chantal Nardin : il y avait trois salons, je crois, dans la nef même, ça devenait la colonne vertébrale de l'exposition. C'était très bien. Mais je crois que j'aime, en tant que regardeuse, avoir du temps et de la matière pour entrer dans un travail, c'est ainsi que je me sens remuée, ouverte, réactive. J'ai besoin de nourriture pour pouvoir en être impactée. Parfois une installation m'enchante, et me produit un contentement fort et immédiat. Mais il me reste plus le souvenir du choc que de la nourriture à penser. Un certain nombre de personnes sont sorties en me disant «quand je sors, je pense ». Ça m'a touchée. Je cherche encore, à chaque fois, comment je vais faire. C'est excitant.

\section{NOTES}

1. Madé, peintre-sculpteure, utilise également ce terme, qui pour elle mêle plutôt les mots structure et mobile, structure et stabile. Cf les Structiles (1997) dans la collection du FRAC Bourgogne.

2. Voir le dossier de présentation du projet : https://www.terreaciel.net/Marcher-les-joursun-echange-de-289. Yves Di Manno, Terre ni ciel. Paris : éditions Corti, 2014.

3. http://christine.delbecq.free.fr/?-Textes-sur-le-travail-

\section{AUTEURS}

\section{VALÉRIE MORISSON}

Valérie Morisson, Maître de Conférences en anglais à l'Université de Bourgogne, Dijon, est l'auteure d'une thèse portant sur l'art irlandais contemporain et ses rapports à l'identité nationale. Elle a publié plusieurs articles relatifs à la culture visuelle irlandaise (arts visuels, 
photographie et illustration, bande-dessinée) mettant en exergue le passage du nationalisme au postnationalisme culturel. Ses recherches sur la photographie contemporaine irlandaise et sur l'œuvre d'artistes féministes montrent que l'art et les pratiques artistiques interrogent l'histoire, la mémoire et les pouvoirs de l'image au sein de sociétés en constante mutation. Ses recherches actuelles se concentrent sur l'art contemporain, irlandais et britannique, et accordent une importance particulière au processus créatif.

Université de Bourgogne

\section{CHRISTINE DELBECQ}

Christine Delbecq est née en 1955 à Mâcon (Saône et Loire). Diplômée des Beaux-Arts, licencée en Histoire de l'art (université Lyon 2), elle devient assistante du sculpteur Josef Ciesla, à Artas (Isère) en 1979 et 80. L'atelier est un lieu fondamental, renouvelé au cours de ses diverses habitations (Mâcon, Lyon, Troyes, Dijon, Saint-Apollinaire). Matériaux diversifiés, lectures, études d'artistes, rencontres, servent de corde tenue à l'évolution de son travail. Et il y a les voyages, toujours des expériences artistiques, qui lui permettent de se décaler par rapport à l'ancrage de l'atelier, de faire bouger les lignes en l'instabilisant : Volgograd, BaÏa Mare, Arnstadt, Montréal, Ilulissat, Montréal, Bombay, ont été le cadre d'échanges artistiques et de résidences dont on retrouve les traces dans son œuvre. Christine Delbecq construit prioritairement un espace de rencontres, elle présente - comme dans la grande exposition de l'été 2021 dans l'église Saint-Philibert de Dijon - des travaux en résonance les uns avec les autres, où chacun est éclairé, dynamisé par sa relation avec les travaux adjoints. Installations, photographie, dessins au crayon de papier, courtes vidéos, maquettes, se répondent et construisent un cheminement en oscillant entre minuscule et immense, dans un écart de perception qui fascine l'artiste. 